\title{
Imaging of Congenital Skeletal Disorders
}

\author{
Maria Pilar Aparisi Gómez, MBChB, FRANZCR ${ }^{1,2}$ Giovanni Trisolino, MD ${ }^{3}$ Luca Sangiorgi, MD 4 \\ Giuseppe Guglielmi, MD ${ }^{5,6}$ Alberto Bazzocchi, MD, $\mathrm{PhD}^{7}$
}

1 Department of Radiology, National Women's Ultrasound, Auckland

Address for correspondence Alberto Bazzocchi, MD, PhD, Diagnostic City Hospital, Auckland, New Zealand and Interventional Radiology, IRCCS Istituto Ortopedico Rizzoli, Via G.

2 Department of Radiology, Hospital Vithas Nueve de Octubre, C. Pupilli 1, 40136 Bologna, Italy (e-mail: abazzo@inwind.it).

Valencia, Spain

3 Pediatric Orthopedics and Traumatology, IRCCS Istituto Ortopedico Rizzoli, Bologna, Italy

${ }^{4}$ Rare Skeletal Diseases, IRCCS Istituto Ortopedico Rizzoli, Bologna, Italy

${ }^{5}$ Department of Radiology, Hospital San Giovanni Rotondo, San Giovanni Rotondo, Italy

${ }^{6}$ Department of Radiology, University of Foggia, Foggia, Italy

${ }^{7}$ Diagnostic and Interventional Radiology, IRCCS Istituto Ortopedico

Rizzoli, Bologna, Italy

Semin Musculoskelet Radiol 2021;25:22-38.

\begin{abstract}
Keywords

- musculoskeletal

- rare disease

- radiography

- skeletal dysplasia

- congenital

Osteochondrodysplasias are the result of the expression of gene mutations. The phenotypes in osteochondrodysplasias evolve through life, with the possibility that previously unaffected bones may be involved at later stages of growth. Due to the variable time of onset, the diagnosis may be made prenatally, at birth, or later. Certainty in the diagnosis is sometimes only achieved as the patient matures and the disease evolves. Radiographic evaluation is a fundamental part of the diagnostic workup of congenital skeletal disorders and in most cases the first tool used to arrive at a diagnosis. This review describes the imaging characteristics, specific signs, and evolution of several skeletal dysplasias in which diagnosis may be directly or indirectly suggested by radiologic findings. A definitive accurate diagnosis of a congenital skeletal abnormality is necessary to help provide a prognosis of expected outcomes and to counsel parents and patients.
\end{abstract}

The constitutional disorders of bone are divided into two large groups: the dysostoses and the osteochondrodysplasias.

Dysostoses are the result of abnormalities in embryogenesis that occur from week 3 to week 8 of development in utero. They result in defective morphogenesis of the skeletal system, with changes in the bones (dysostoses may involve one or multiple bones) that may progress locally but will not spread to involve previously normal bones or joints. The phenotype of dysostoses is static through life. ${ }^{1}$ Due to their very early onset in most cases, it is almost always possible to make a prenatal diagnosis.

Osteochondrodysplasias are the result of the expression of gene mutations and classified into two different groups: the dysplasias, which consist of abnormalities of bone or cartilage growth, and the osteodystrophies, which are abnormalities of bone or cartilage texture.

The largest group are the dysplasias. The phenotypes in osteochondrodysplasias evolve through life, with the possibility that previously unaffected bones may be involved at later stages. Due to the variable time of onset, the diagnosis may be made prenatally (generally in the most severe cases), at birth, or later. Certainty in the diagnosis is occasionally only achieved as the patient grows and the disease evolves. ${ }^{2}$

Based on radiologic, molecular, and biochemical criteria, $>450$ different osteochondrodysplasias exist. ${ }^{3,4}$ The overall prevalence has been estimated as 2.3 to 7.6 in 10,000 births.,

The diagnosis of dysplasia in many cases is done prenatally. Certainly the most severe cases, which may be lethal perinatally,
Issue Theme Imaging of Pediatric MSK Diseases; Guest Editors, Alberto Bazzocchi, MD, PhD and Giuseppe Guglielmi, MD (c) 2021. Thieme. All rights reserved. Thieme Medical Publishers, Inc., 333 Seventh Avenue, 18th Floor, New York, NY 10001, USA
DOI https://doi.org/ 10.1055/s-0041-1723964. ISSN 1089-7860. 
are normally evident on antenatal scans, although some nonlethal dysplasias may already be evident at that point. In other cases of dysplasia (obviously nonlethal), manifestations only appear later, and the diagnosis is achieved from the evaluation of clinical and family history, physical examination, radiologic assessment, and molecular/biochemical tests.

Radiologic evaluation is a fundamental part of the diagnostic work-up. This review focuses on how to recognize a range of skeletal dysplasias that are fundamentally nonlethal, not necessarily diagnosed in utero, in which diagnosis may be oriented toward or directly suggested by radiologic findings and specific signs. We based our review of imaging findings on anatomical involvement, at the general and bone level, and intrinsic bone characteristics. Note that this article complements the article on embryology of the skeletal system in this issue of the journal.

\section{Diagnosis}

\section{Approach to Diagnosis}

The number of different entities is phenomenal (461). ${ }^{4}$ The classification changes as molecular bases are described. The 2019 revision of the nosology and classification of genetic skeletal disorders has 42 groups of conditions, essentially the same as the 2015 revision $^{7}$ but two more than in $2010 .^{3}$

Pathogenic variants affecting 437 different genes were found in 425 of the 461 (92\%) of these conditions. Approximately 100 of the 461 diseases present prenatally. ${ }^{8}$

The revisions of this classification are frequent and very relevant; they are invaluable diagnostic aids. The classification is not always based on the same criteria; some diseases are grouped based on the causal gene, and others are listed together because they have similar radiologic features. Some others are grouped based on their clinical course (lethality) or because they involve similar parts of the skeleton. Roughly the first eight groups of the classification are grouped based on molecular background, and the following 34 are organized according to clinical and radiologic presentation.

\section{Antenatal Work-up}

The evaluation of fetuses in the second trimester for the detection of abnormalities currently represents the standard of care in most communities. The skeleton develops early in the fetal period, and therefore the prenatal diagnosis of skeletal disorders is feasible. The different components of the fetal skeleton can be easily seen, and limb bones can be measured from week 11 to $12 .^{9-11}$

The measurement of fetal limbs is useful to date pregnancies, and it constitutes an important part of the assessment of fetal anatomy. ${ }^{12}$ Growth has to be related to characteristics of the population, or nomograms, and the increase in length is linear throughout gestation. ${ }^{13}$ Among limb measurements, the femur length is the most commonly used, included in regular growth scans as one of the parameters to assess growth and to obtain an estimate of fetal weight. ${ }^{14}$

The incidental discovery of skeletal abnormalities on routine second-trimester ultrasound (US) in a pregnancy not at risk of a specific syndrome requires a systematic examination of the limbs, thorax, and spine to help determine the correct diagnosis.

When the femoral or humeral measurements are $<5$ th percentile or $<2$ standard deviations (SDs) from the mean in the second trimester, specialist assessment (fetal medicine referral) should be made for a complete evaluation of the skeleton. ${ }^{15}$ If a dysplasia is diagnosed, genetic counseling is paramount.

In some cases, in which family history exists, there is already a known risk. Surveillance should then be exhaustive, with both segments of all limbs specifically measured.

Dedicated assessment of the skeleton should include analysis of all long bones (length, shape, echogenicity), fetal head and cranium (biparietal diameter, occipitofrontal diameter, head circumference), facial profile (glabellar bossing, flattened nasal ridge, micrognathia), mandible, clavicle, scapula, spine (number and shape of the vertebral bodies), hands and feet (number and shape of digits), chest circumference, and abdominal circumference.

Obtaining a list of the elements of the skeleton that are abnormal, as well as documenting the mineralization and shape of the bones, is very important to narrow the diagnosis. ${ }^{15,16}$ When measurements of the long bones are $<3$ SDs from the mean, suspicion of skeletal dysplasia should be very high, especially if the head circumference is $>75$ th percentile. Most dysplasias with a prenatal onset demonstrate a relative disproportion of skeletal measurements compared with the measurements of the fetal head. Also, many skeletal dysplasias are associated with abnormalities in the hand and feet. ${ }^{16}$

Diagnosis cannot be reached with confidence in a very high number of cases. However, one of the most important tasks for prenatal US in the context of a skeletal abnormality is to determine the neonatal or infantile lethality of the condition, which is normally linked to small chest circumference that leads to pulmonary hypoplasia and early postnatal death.

Several criteria are used to assess lethality: the most common are the chest-to-abdominal circumference ratio $(<0.6)^{17}$ and the femur length-to-abdominal circumference ratio $(<0.16) .{ }^{18}$ These are strongly linked to lethality.

Lethality has to be put in perspective with the concurrence of other abnormalities in other systems. Long bone shortening, decreased bone echogenicity, and marked bowing or fractures are also linked to lethality. ${ }^{19,20}$

The accuracy of diagnosis of dysplasias in prenatal US ranges between $40 \%$ and $60 \%,{ }^{21,22}$ which is why subsequent radiologic evaluation (babygram, anteroposterior [AP] and lateral views from head to foot) and eventually autopsy and histomorphic analysis (especially cartilage, in the rare ones) ${ }^{23}$ is still very important, even in lethal dysplasias. It is critical to reach an accurate diagnosis when possible to offer counseling and thus avoid recurrence (many dysplasias have a high recurrence risk). ${ }^{15}$

Prenatal US has evolved significantly in the past few years. The use of three-dimensional (3D) techniques (e.g., possibility of rendering to see small structures better, analysis in different anatomical planes, tomographic analysis thanks to 3D data sets) has improved visualization and, obviously, evaluation. 
The use of low-dose $\mathrm{e}^{24-26}$ and ultra-low-dose computed tomography $(\mathrm{CT})^{27}$ was explored and proven to be very helpful. ${ }^{28}$ The main advantage of the use of low-dose CT for the evaluation of fetuses is the exquisite depiction of fetal bones and the possibility of complete 3D rendering of the skeleton. Images can be rotated in space and postprocessed to focus on particular sections and to obtain adequate detail. This is an important advantage with respect to dedicated US, in which the maternal habitus and the position of the fetus have a great impact on visualization.

Low-dose CT allows retrospective study of the skeleton that is useful in cases in which fetuses have to be fragmented on evacuation, to help the geneticist and pathologist in the reconstruction. The possibility to obtain 3D renderings of the full skeleton is useful for obstetricians and orthopaedic surgeons to plan delivery and potentially postnatal surgery, and it is also very helpful for parents to understand the extent of the anomalies. ${ }^{26}$

The use of CT is a serious decision, normally made by a multidisciplinary team of sonographers, radiologists, fetal medicine experts, obstetricians, geneticists, and surgeons, because it requires radiation. The potential benefits need to be carefully weighed against risks. The study is usually considered if the diagnosis has not been achieved with highly detailed specialist US examination and parents agree in an informed consent.

Multiple studies have evaluated the performance of lowdose fetal CT, placing it at a superior level than US. ${ }^{25,28}$ Ruano et $\mathrm{al}^{29}$ in a comparative study of 33 patients, reported that two-dimensional US had an accuracy of 51\%; 3D US, 77\%; and fetal CT, $94 \%$.

Miyazaki et al ${ }^{30}$ compared its performance with postnatal radiological skeletal survey, finding that CT had a $94 \%$ rate of identification of cardinal findings and a 100\% accuracy in diagnosing skeletal dysplasias in individual patients (including common and uncommon dysplasias). In 59\% of the cases, fetal CT changed the diagnosis obtained with US, with important consequences. An additional advantage of fetal CT is that it may reveal additional findings, narrowing the differential. ${ }^{25}$

According to the American College of Radiology/Society for Pediatric Radiology guidelines for imaging of a pregnant patient, the effect of a $50-\mathrm{mGy}$ radiation dose is negligible. The American College of Obstetricians and Gynaecologists ${ }^{31}$ released a statement that exposure to $<5 \mathrm{rad}(50 \mathrm{mGy})$ is not associated with an increase in fetal anomalies or pregnancy loss. This position is shared by the International Commission on Radiological Protection and the National Council on Radiation Protection.

If a fetus is not exposed to radiation during pregnancy, the chance of being born with no malformations is $96 \%$, the chance of being born with no childhood cancer is $99.93 \%$, and the cumulative chance of being born with no malformation and no childhood cancer is $95.93 \%$. With a radiation of $5 \mathrm{mSv}$, these percentages decrease to $95.99 \%, 99.89 \%$, and $95.88 \%$, respectively. With a dose of $50 \mathrm{mSv}$, they decrease to $95.90 \%$, $99.51 \%$, and $95.43 \%$, respectively. ${ }^{32}$

The International Commission on Radiological Protection states that "When pregnant women require abdominal or pelvic diagnostic X-ray examinations in which the X-ray beam irradiates the fetus directly, special care has to be taken to ascertain that the X-ray examination is indeed indicated at that time and that it cannot be delayed until after the pregnancy. Commonly, the radiation risk to the fetus is much less than that of not making a necessary diagnosis. In such cases, care should be taken to minimize the absorbed dose in the fetus. However, alterations in technique should not unduly reduce the diagnostic value of the X-ray examination." ${ }^{33}$

To optimize the risk-benefit ratio, these studies should be performed in scanners with multiple detectors (as many as possible, to reduce scanning time and therefore avoid movement artifact), using low peak kilovoltage (as low as possible for patient habitus), decreased pitch in association with rapid gantry rotation (to minimize scanning time and optimize signal-to-noise and contrast-to-noise ratios for dose), and manipulating the automatic tube current-time setting or automatic exposure control (milliamperes per second, keeping in mind the potential increase in noise).

A very important factor to decrease radiation dose is the shape of the iterative reconstruction (IR), which belongs to the postprocessing phase and as such does not involve radiation, but allows adjustments in protocols so that lower doses can be used, preserving the level of accuracy. For example, Imai et $\mathrm{al}^{27}$ proposed a threshold of $0.5 \mathrm{mSv}$ as the minimal radiation dose for ultra-low-dose fetal CT without losing image quality, using model-based iterative reconstruction (MBIR), a specific tool for postprocessing.

Low-dose CT is performed during the second and third trimester of pregnancy (ideally from week 20 but not before week 18$)^{25,26}$ when organogenesis is already complete. In most cases, indication of low-dose $\mathrm{CT}$ is limited to mothers with a challenging body habitus. In these patients, unfortunately, the radiation dose has to be larger than in normal body habitus patients to be able to traverse the maternal abdomen and adjust for noise, which increases radiation to the fetus. It is important to highlight that if correct reasonable indications are followed, fetal low-dose CT is normally performed in a pathologic context of severe abnormalities, most of which are lethal. ${ }^{26}$

\section{Radiologic Evaluation}

If a skeletal dysplasia is suspected, a skeletal survey needs to be performed. It consists of a series of radiographs that sample the structure and morphology of a wide range of bone structures. Ideally this should include the following images ${ }^{2,34}$ :

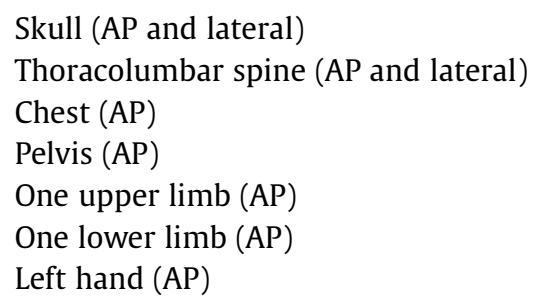

The left hand is included to assess bone age. This is important in some cases in which it is necessary to relativize findings to the stage of normal growth. ${ }^{35}$ For example, if a child is short constitutionally, while the fingers may be short 
in comparison with another child of the same age, they may be normal for the child, related to height. Bone age may also be obtained from the foot and ankle, or the knee.

If the limbs are visibly asymmetric or if epiphyseal involvement or stippling is suspected, views of both limbs (upper and lower) should be obtained for more accurate assessment. In some cases, it may also be useful to obtain dedicated views (projections) that would better display the abnormality.

If other family members are affected, or at least suspected to have the same condition, it may be useful to obtain radiologic surveys (and previous imaging) from them. This may offer an insight on future appearances, for example, and aid with diagnosis and prognosis. Inherently, it also gives information (or confirmation) on the pattern of inheritance.

Dysplasias are evolving diseases. When a diagnosis cannot be reached initially, it is helpful to repeat the survey, but it should not be done too early. Most centers would not repeat in $<12$ months. $^{2}$

Serial radiographs and comparison are essential to evaluate evolution and complications. An important consideration is that early radiographs are very useful. The ideal age for recognition of most dysplasias is before the closing of the growth epiphyses, after which a radiologic diagnosis may be impossible. ${ }^{36}$

\section{Approach to Radiologic Analysis}

Any radiologist specialized in the analysis of musculoskeletal (MSK) structures, regardless of their experience with pediatric patients, is likely to encounter clinical questions regarding skeletal dysplasias and will have to evaluate skeletal surveys performed with this purpose.

An important consideration is that orthopaedic management does not necessarily require a complete diagnosis of certainty. The patient can be treated with the clinical and radiologic approach to the problem, and in this sense, the role of the MSK radiologist is very helpful as the usual correlate of the orthopaedic surgeon. Analysis of findings from the pure MSK perspective is important to speed up treatment.

Final diagnosis is still necessary to aid the pediatrician and geneticist and provide a prognosis in terms of expected outcomes in adulthood, and to counsel parents and patient. In this sense, a careful radiologic assessment is also paramount. An accurate diagnosis also opens up possibilities of support, psychological but also in many instances institutional/economical, which is paramount.

For this same reason, misdiagnosis (in the sense of failure to label an entity correctly) may pose a tremendous problem with devastating consequences for the patient and families, either not allowing them to benefit from the best management approaches or creating a stigma.

A reasonable general approach to the analysis of radiologic findings was suggested by Offiah and Hall, ${ }^{2}$ based on the simplicity of the A, B, C, D mnemonic. "A" stands for anatomical involvement, which is really helpful as a starting point for classification. " $\mathrm{B}$ " stands for bone characteristics that will involve the analysis of five "S": structure, shape, size, sum, and soft tissues.

Structure refers to bone density (deficient or excessive) and presence of tumors (exostoses or internal abnormalities).
Shape comprises a large list of descriptive terms affecting portions or the whole bone (some of these descriptions are very helpful for classification because they are typical of certain groups). Size abnormalities may be absolute or relative to other bones in the individual. Sum refers to the "number" of bones: excessive, absent, or fused. Soft tissue refers to the analysis of other findings in radiographs: wasting, excessive soft tissues, calcifications, and contractures.

"C" stands for complications that may be fractures, subluxations/luxations, scoliosis, limb discrepancies, and development of malignancy. "D" stands for death, whether the findings are compatible with life, which is critical for counseling.

All these characteristics, in careful analysis, are very helpful to narrow suspicion of the diagnosis, which ultimately needs to be genetically confirmed/correlated.

Partially based on the general approach just outlined, we describe the most frequently encountered dysplasias in which diagnosis may be narrowed or suggested by radiologic findings. We grossly base our review of imaging findings on anatomical involvement, at the general and bone level, and intrinsic bone characteristics. We also focus on the ones that do not correspond to the lethal type, which are normally diagnosed in the antenatal period.

\section{Imaging Characteristics of Dysplasias}

\section{Dysplasias with Shortening of Bones}

In dysplasias with shortening of bones, metaphyseal abnormalities are predominant, impairing normal growth of bones. The shortening of the limbs can be rhizomelic, as seen in achondroplasia, hypochondroplasia, and thanatophoric dysplasia (lethal), or be mesomelic or acromelic, as seen in chondroectodermal dysplasia (Ellis-Van Creveld syndrome), Jeune's/asphyxiating thoracic dysplasia (lethal), and short-rib polydactyly dysplasias.

\section{Achondroplasia}

Achondroplasia is the most common nonlethal dysplasia. It is inherited in an autosomal dominant fashion; 80\% occur sporadically. The cause is a mutation in chromosome 4 involving the fibroblast growth factor receptor 3 (FGFR3). ${ }^{37}$

The typical features are present at birth. Prenatal diagnosis may be challenging, given that this condition may only be revealed in the third trimester when it becomes evident there is shortening of the long bones. The abnormalities involve the limbs, spine, pelvis, and skull ${ }^{37,38}$ (-Fig. 1).

There is symmetrical shortening of all the long bones, with the proximal portions and the lower limbs more affected (rhizomelia). The metaphyses are splayed, with normal epiphyses. In the immature skeleton, the epiphyses appear closer to the metaphyses, and therefore articular (cartilage) spaces appear widened. On occasion the metaphysis appears to "wrap" around the epiphysis, with a "ball-socket" appearance. This appearance is frequently seen in the distal femur and attenuates/resolves with skeletal maturation.

The hand bones are tubular shaped and thick (second to fifth metacarpals and proximal phalanges more affected), with 

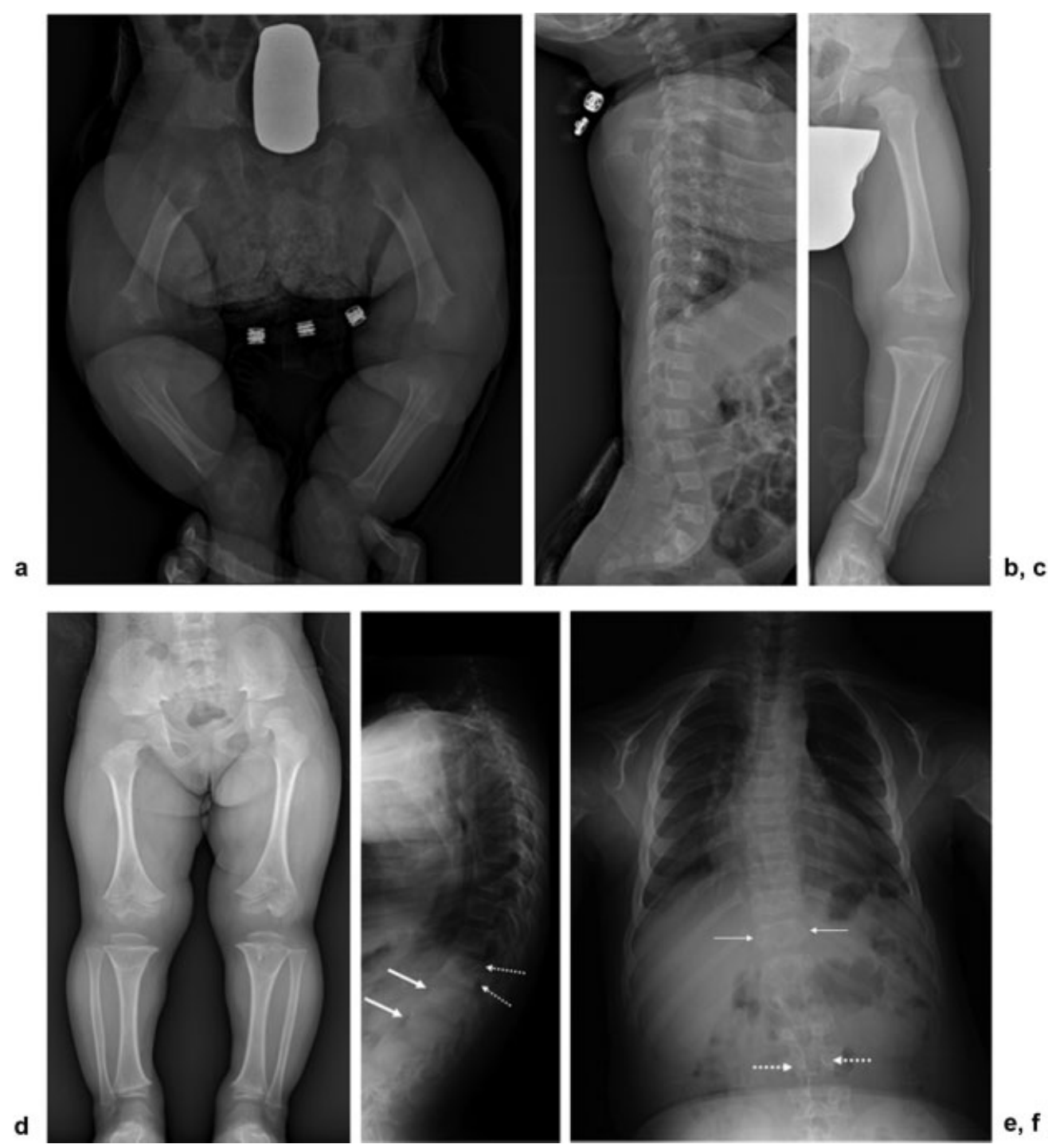

Fig. 1 Achondroplasia through different stages of development. The typical features of achondroplasia are already present at birth. (a) Radiograph of lower limbs of a 2-month-old girl. There is symmetrical shortening of all the long bones, with the proximal portions and the lower limbs more affected (rhizomelia). The metaphyses already appear splayed. (b) There is exaggerated sacral tilt and a protruding sacral promontory, seen in the lateral spine view. (c) Detail of leg radiograph in a 4-year-old boy. In the immature skeleton, the epiphyses appear closer to the metaphyses, and therefore articular spaces appear widened. (d) Anteroposterior (AP) radiograph of pelvis and lower limbs in a 6-year-old girl demonstrate the typical appearances of the pelvis, short and broad ("champagne glass" appearances) with "elephant-ear shaped" iliac wings. The inferior margins of the iliac wings and acetabular roofs are flattened and horizontal. (e) Lateral view of the spine of a 9-year-old boy. The overall length of the spine is normal, as are vertebral body heights. The vertebral bodies may have a "bullet-shaped" configuration, with a rounded anterior aspect (arrows) and a scalloped posterior aspect (dotted arrows). (f) On AP view, an important finding is the progressive caudal decrease in the interpeduncular space in the lumbar spine that will become more conspicuous with age, with development of spinal stenosis (thin arrows show normal distance; dotted arrows demonstrate a level of decrease of the interpeduncular space).

a pronounced irreducible gap on extension of the second and third fingers that makes them look like a "trident."

The pelvis is short and broad ("champagne glass" appearances) due to squaring of the iliac wings, "elephant-ear shaped." The inferior margins of the iliac wings and acetabular roofs are flattened and horizontal.

Exaggerated sacral tilt and a protruding sacral promontory are characteristic. There is associated dorsolumbar kyphoscoliosis when sitting, with lumbar hyperlordosis on a standing position. The overall length of the spine is normal, as are vertebral body heights. An important finding is the progressive caudal decrease in the interpeduncular space in the lumbar spine that will become more conspicuous with age, with development of spinal stenosis. In the lateral view, the vertebral bodies may have a "bullet-shaped" configuration, with a rounded anterior aspect and a scalloped posterior aspect.

The skull has a narrowed base, with narrowing of the foramen magnum. The vault is expanded with frontal bossing. There is midface underdevelopment, relative to the size of the vault.

Prenatally, it may eventually pose challenges to be distinguished from thanatophoric dysplasia. In childhood, the differential diagnosis has to be made with hypochondroplasia. ${ }^{39}$

\section{Hypochondroplasia}

Hypochondroplasia is a milder form of achondroplasia, caused by a mutation in the gene encoding FGFR3. ${ }^{39}$ Other 


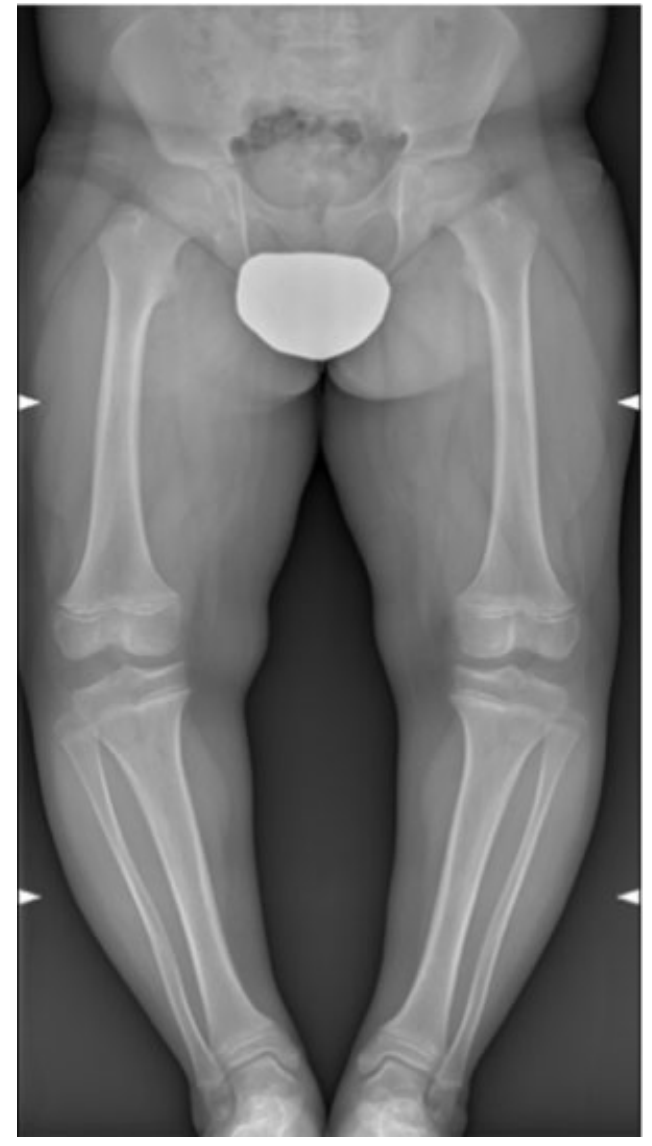

Fig. 2 Hypochondroplasia. Anteroposterior radiograph of the lower limbs in an 11-year-old boy. Manifestations appear later than achondroplasia, with short stature and limb shortening that becomes evident as the child starts to grow.

mutations in chromosome 4 that do not involve this gene but another $(S H O X)$ that also affect stature were described. ${ }^{40}$

Manifestations appear later than achondroplasia, with short stature and limb shortening that becomes evident at age 2 to 4 (-Fig. 2). The findings in the spine are similar to achondroplasia. Interpeduncular distance is also reduced caudally, but spinal stenosis is less common. In the limbs, there can be rhizomelia but also mesomelia. ${ }^{41}$

The skull, pelvis, and hands are essentially normal. There may be mild macrocephaly and mild brachydactyly involving all metacarpals and phalanges. ${ }^{42}$

\section{Chondroectodermal Dysplasia (Ellis-Van Creveld)}

Chondroectodermal dysplasia is recessively inherited, due to a mutation in the EVC gene in chromosome $4 .{ }^{43}$ The condition is evident at birth, with the detection of dysplastic nails, teeth, polydactyly, and congenital cardiac defects $(60 \%$ of individuals). ${ }^{44}$ The most common one is a defect of primary atrial septation, with a common atrium as a result. ${ }^{45}$

There is mesomelia and acromelia, with postaxial hexadactyly in hands and feet, and carpal fusion that involves the capitate and hamate. The pelvis is short with flared iliac wings, a narrow base, and hook-like projection from the acetabulum, forming a "trident" acetabula. The spine remains normal throughout.
Other findings are genu varum and acro-osteolysis, synmetacarpalism and synphalangism due to progressive involvement. $^{46}$

Jeune's dysplasia and short-rib dysplasia with or without polydactyly may have similar radiologic features, but the involvement of other organs like teeth, nails, and the heart are typical of chondroectodermal dysplasia.

\section{Dysplasias with Abnormal Epiphyses}

In some dysplasias, abnormal epiphyses are the predominant finding. In these cases, the abnormalities lead to early osteoarthritis and joint deformities.

This is a broad group. The involvement may be isolated to the epiphysis, as in chondrodysplasia punctata. In some entities, there is concomitant involvement of the spine (platyspondyly), as in the type II collagenopathies (spondyloepiphyseal dysplasia congenital and tarda, Kniest dysplasia, and achondrogenesis type II). In some other cases, along with epiphyseal involvement, there may be metaphyseal involvement (spondyloepimetaphyseal dysplasia, multiple epiphyseal dysplasia, pseudoachondroplasia, mucopolysaccharidoses, diastrophic dysplasia, and achondrogenesis type I).

\section{Chondrodysplasia Punctata}

Chondrodysplasia punctata (CDP) is a genetically heterogeneous dysplasia (different genetic causes), with the common characteristic of stippling of the epiphyses. The most commonly encountered one is X-linked dominant, also called the Conradi-Hunermann type. ${ }^{47,48}$

This condition is almost exclusively seen in females and normally lethal in males. Radiographically, there is stippling of the epiphyses that typically involves hands and feet, rhizomelia, transient congenital ichthyosis, patchy alopecia, cataracts, and midface hypoplasia. In the spine, there is stippling of the end plates and bodies that disappears over time, with development of kyphoscoliosis. These infants have normal mental development.

Another type is rhizomelic chondrodysplasia punctata (RCDP), associated with a peroxisomal enzyme disorder and autosomal recessive inheritance. ${ }^{49}$ There are several types (I, II, III); the most common is type I. It is characterized by rhizomelia, broad nasal bridge, epicanthus, high-arched palate, dysplastic ears, micrognathia, congenital contractures, and ocular problems. Contrary to the more benign Conradi-Hunermann type, stippling involves large joints and spares hands and feet, and in the spine, there is no stippling, but there are coronal clefts. Normally there is severe mental retardation and spasticity. It is lethal, with patients not surviving beyond the first decade. ${ }^{49}$

Another very rare type of CDP of genetic origin is the brachytelephalangic type, with $\mathrm{X}$-linked recessive inheritance. ${ }^{50} \mathrm{CDP}$ can also occur in cases of embryotoxicity by warfarin (milder type, similar to Conradi-Hunermann) and in infants from mothers with autoimmune diseases (systemic lupus erythematosus) with features similar to RCDP, but with longer survival. ${ }^{51}$

When stippling of the epiphyses is encountered radiographically, the most important differential is between 
Conradi-Hunermann type and RCDP, given the prognosis is quite different. Distribution of the stippling is really helpful (Conradi-Hünermann typically involves hands, feet, and spine).

\section{Spondyloepiphyseal Dysplasia Congenita (SEDC)} Spondyloepiphyseal dysplasia congenita (SEDC) is a type II collagenopathy, with autosomal inheritance. The typical deformities of SEDC begin before birth and include malformations that predominantly involve the spine, hips, and knees, and abnormalities that affect the eyes (myopia and vitreoretinal degeneration, retinal detachment) and ears (progressive sensorineural hearing loss). Malar hypoplasia and cleft palate are also seen. Intelligence is unaffected, but there may be delays in attaining milestones, due to delayed growth, muscular hypotonia, and spinal malformations. Gait may be abnormal, with "waddling." 52,53

Typical features are a very short stature (disproportionate dwarfism, arms appear long compared with torso), with flattened vertebral bodies and abnormal epiphyses. The typical radiologic feature is delayed ossification of the epiphyses, not present at birth. ${ }^{52}$

Manifestations mainly involve the spine. The vertebrae are bulbous, pear-shaped at birth, and then flatten, in keeping with severe platyspondyly. The intervertebral spaces are very thin. Over time, kyphoscoliosis develops, as well as lumbar lordosis and atlantoaxial instability secondary to odontoid hypoplasia, with risk of compressive myelopathy. ${ }^{53}$

Pubic bones are absent at birth, and the iliac wings are short and broad. The roofs of the acetabulum are flat as a consequence.

The epiphyses of the knee and the calcaneum are not present at birth. The ossification of the carpal and tarsal bones is delayed but not that of other bones in the hands and feet.

The skull is usually large and dolichocephalic, and there is rhizomelic shortening of the limbs, more in the lower than the upper. The metaphyses appear widened because of the abnormal epiphyses.

Joint stiffness and deformities (coxa vara, genu varum or valgum, luxations), and early-onset osteoarthritis develop over time.

\section{Spondyloepiphyseal Dysplasia Tarda}

Spondyloepiphyseal dysplasia tarda (SEDT) is a condition with a diverse inheritance (X-linked recessive, classically, but autosomal recessive and dominant have also been described). As X-linked recessive, it only affects males.

The age of presentation, as the name indicates, is later than in the congenital form, $\sim 5$ to 10 years, but it can be variable, even in the second decade of life. ${ }^{54}$ Appearances at birth are normal.

In the spine, there is platyspondyly, with hyperostosis in the posterior two thirds of the bodies that gives them "humped" appearances. Progressive narrowing of the interpeduncular distances was also described. ${ }^{55}$

The pelvis is small, with mild epiphyseal irregularity, leading to early osteoarthritis in the hips, knees, and ankles. Hands, feet, and skull are typically not involved. Cleft palate and retinal detachment, typical of SEDC, are not seen in SEDT. ${ }^{53}$

\section{Kniest Dysplasia}

Kniest dysplasia is another type II collagenopathy, with an autosomal dominant inheritance. It is similar to SEDC, with a markedly short trunk and delayed ossification at birth and infancy. ${ }^{56}$

In addition to the features of SEDC, the femurs are dumbell-shaped, and there is coronal clefting of the spine at birth. With development, the epiphyses become enlarged, becoming "mega-epiphyses," with cloud-like calcifications in the metaphyses.

In the hands, the metacarpals and phalanges are abnormal, with flattening and enlargement of the ends, which makes the metacarpophalangeal and proximal interphalangeal joints look bulbous. ${ }^{57}$

\section{Achondrogenesis Types I and II}

Achondrogenesis types I and II are the most severe types of chondrodysplasia and lethal before or soon after birth. They are normally diagnosed in utero.

Type I is subdivided into IA and IB. ${ }^{58}$ In type I, there is deficient ossification in the lumbar, sacral, pubic, and ischial bones. There is also severe micromelia and a large head, with edema in the soft tissues. ${ }^{59}$ The ribs are thin, with multiple fractures (can be mistaken for osteogenesis imperfecta). Type II is characterized by absent ossification of the spine, the sacrum, and pubic bones.

The trunk is short, small, with a prominent hydropic-appearing abdomen, in both types. Hypochondrogenesis belongs to this group, with a milder phenotype, ${ }^{60}$ and is genetically related.

\section{Spondyloepimetaphyseal Dysplasia}

Spondyloepimetaphyseal dysplasia (SEMD) is a generally descriptive term for a group of entities that demonstrate radiologic abnormalities in the spine, epiphyses, and metaphyses, and they have different phenotypes, mechanisms of inheritance, and particular radiologic findings. There are many different variants.

One of the specific variants is the Strudwick type. ${ }^{61}$ It is characterized by severe dwarfism, pectus carinatum, and scoliosis that may evolve to severe and create problems in adulthood.

Short limbs and delayed epiphyseal maturation are already present at birth. During infancy, the disorder cannot be distinguished from SEDC (cleft palate and retinal detachment, typical of SEDC, are also present in Strudwick SEMD).

The typical radiographic feature is the development in early childhood of irregular sclerotic changes in the metaphyses of the long bones. This pattern (called "dappling") results from a mix of regions of osteosclerosis and osteopenia. ${ }^{62}$ It is usually more marked in the ulna and fibula than in the radius and tibia ( - Fig. $\mathbf{3}$ ).

Some variants of SEMD are well delineated, but in a great number of cases, the approach is basically descriptive (-Fig. 4). As a general rule, in patients in which the epiphyseal component is predominant, there will be early development of osteoarthritis. 


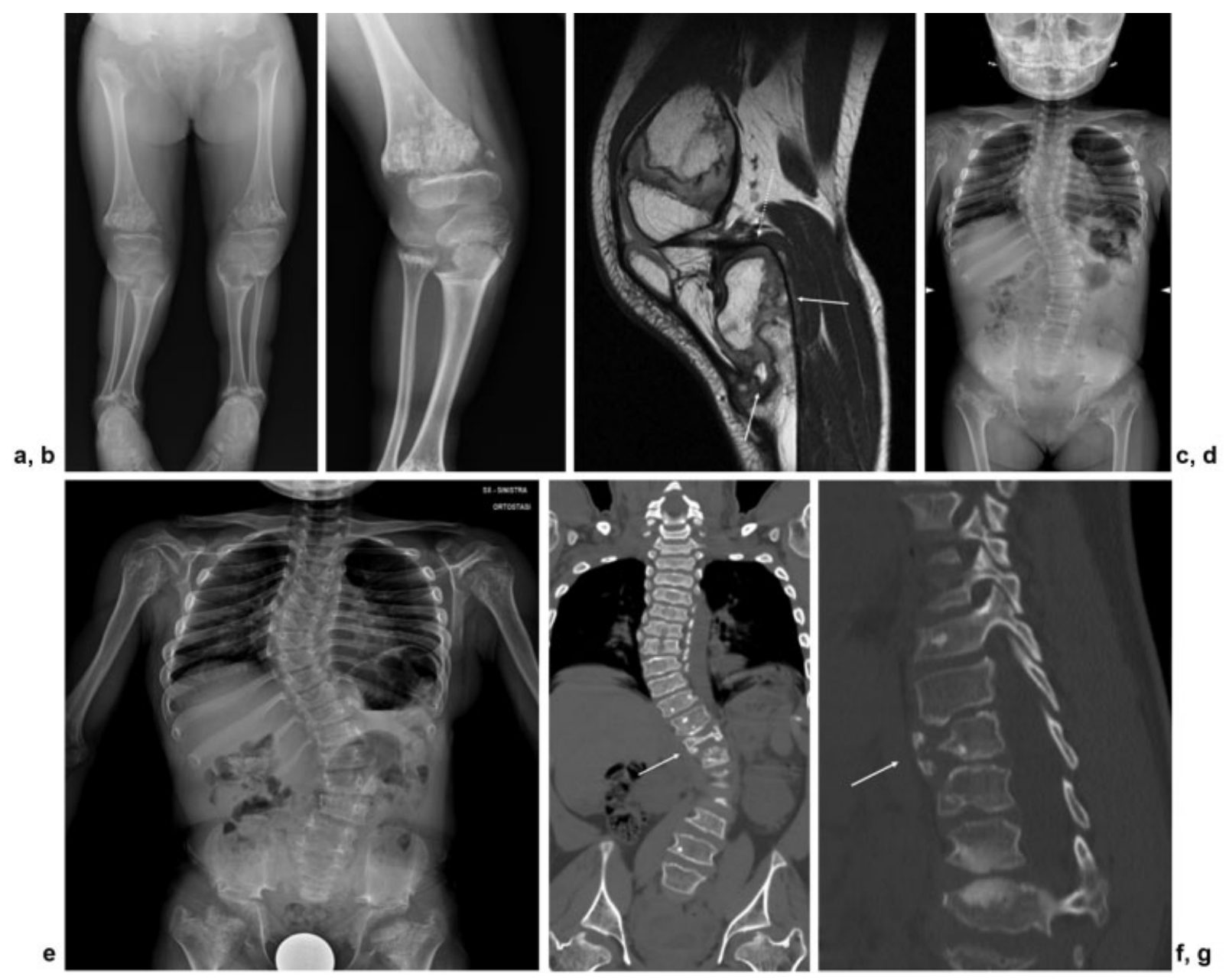

Fig. 3 Spondyloepimetaphyseal dysplasia, Strudwick type. (a) Anteroposterior (AP) radiograph of the lower limbs in a 7-year-old girl demonstrates the typical radiographic feature of "dappling," resulting from a mix of regions of osteosclerosis and osteopenia in all the metaphyses included in the projection, more conspicuous around the knee. (b) This is seen in detail in the radiograph of the right knee. There is a degree of valgus deformity. Short limbs and delayed epiphyseal maturation are already present at birth. (c) Sagittal proton-density view from magnetic resonance imaging of the right knee, performed when the girl was 10, demonstrates the irregularity in the distal metaphysis of the femur and proximal metaphysis of the tibia. In the proximal tibia there are ossified foci within the metaphysis (arrows), and the epiphysis has an abnormal orientation, almost vertical (signaled by the dotted arrow). The girl underwent corrective tibial osteotomies. (d) AP radiograph of the spine of the same girl at 10 years of age. There is marked thoracolumbar scoliosis. "Dappling" is present in the humeral metaphyses, and note the irregularity of the epiphyses. The femoral epiphyses are practically not present, with marked irregularity of the metaphyses ("dappling" is again seen). Note how the iliac wings are short and broad. The roofs of the acetabulum are flat, as a consequence of this and the irregular femoral epiphyses. (e) Three years later, by the time the girl is 13 , the scoliosis has mildly progressed. The appearances of the epiphyses and metaphyses of the humeri and femurs are similar to previous images, markedly irregular. Computed tomography (f) coronal reconstruction and ( $\mathbf{g}$ ) sagittal reconstruction, acquired at 17 years of age. The femoral heads are underdeveloped (practically absent) and the acetabular roofs are flat. There are also segments of platyspondyly and residual fragmentation of the vertebral bodies (arrows).

\section{Multiple Epiphyseal Dysplasia}

Multiple epiphyseal dysplasia (EDM) is a genetically heterogeneous condition, with multiple types. Most are of autosomal dominant inheritance, but recessive forms are also possible. ${ }^{63}$ It normally presents at 2 to 4 years of age when the child starts to walk.

Symptoms include joint pain, in hips and knees, a waddling walk, and short stature as adults. As in other entities involving the epiphyses, there is early onset of osteoarthritis. In recessive inheritance, there may be malformations of the hands, feet, knees, and other abnormalities. Other clinical findings include myopia, sensorineural hearing impairment, and abnormalities of T-cell physiology. Rarely, there can be anonychia (absent nails). ${ }^{64,65}$
There is bilateral and symmetric irregularity of the epiphyses of the hips, knees, ankles, shoulders, elbows, wrists, hands, and feet (-Fig. 5). In the ankle, there is lateral tibiotalar inclination, with the lateral part of the distal tibial epiphysis thinner than the medial, and the talus is shaped to accommodate.

A typical finding is the double-layered patella (pathognomonic), seen in the lateral view ${ }^{64,65}$ (-Fig. 6). This was also described in pseudoachondroplasia, ${ }^{66}$ likely explained by mutations affecting the same genes (genotypic alleles).

The spine is only mildly involved (there is no platyspondyly), with anterior wedging, mild end-plate irregularity, and Schmorl's nodes, resembling Scheuermann's disease. 

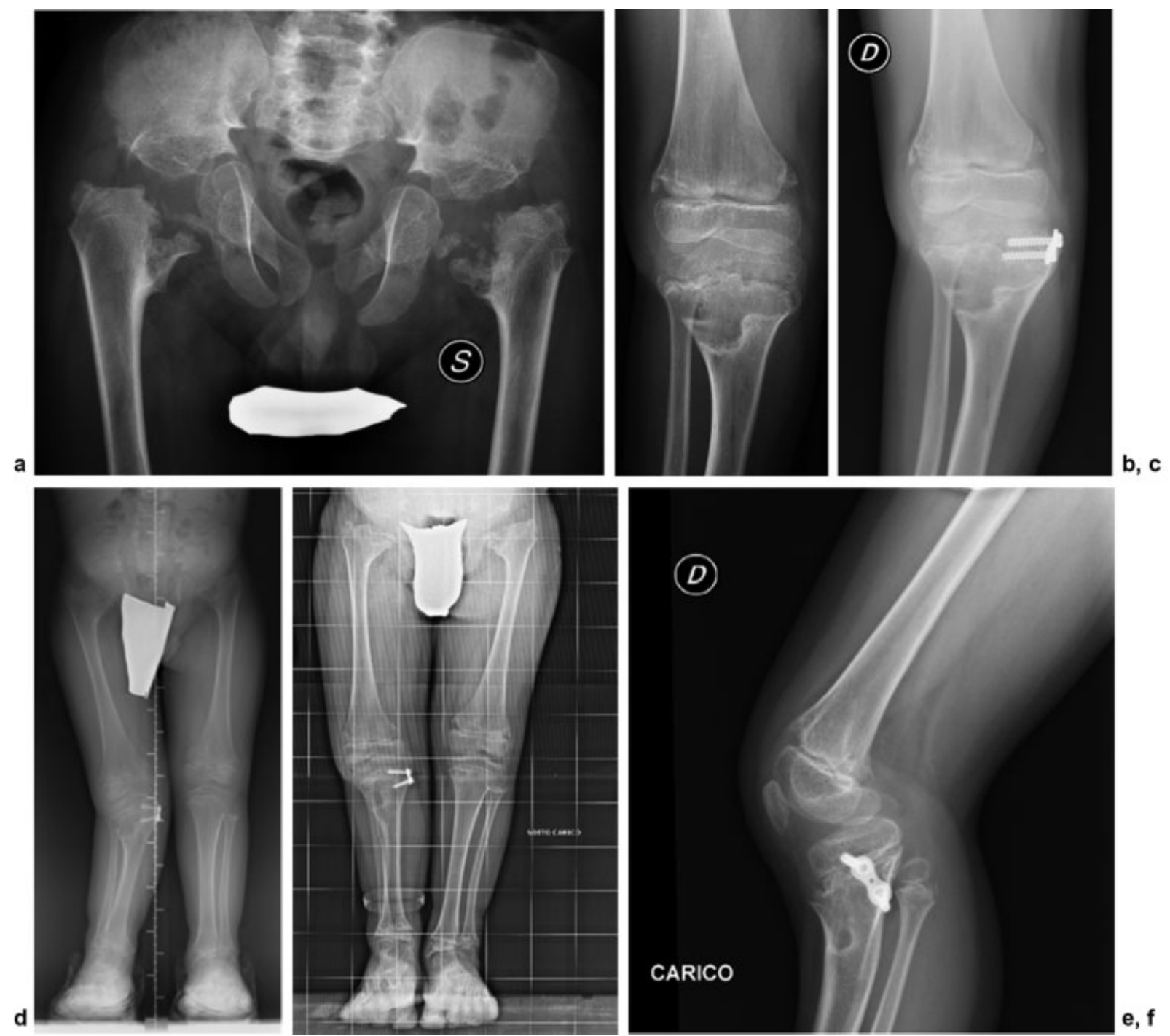

Fig. 4 Spondyloepimetaphyseal dysplasia. Sporadic presentation. First visit at 7 years of age. The diagnosis was confirmed by clinical and radiographic findings, even though the molecular tests (COMP and MANT3) were negative. (a) Anteroposterior (AP) radiograph of the pelvis at 8 years of age demonstrates marked irregularity of the metaphyses and practically nonexistence of the epiphyses that cannot be seen to be ossified. The acetabular roof is flat, and the iliac wings are short and broad. (b) AP radiograph of the right knee (age 8) demonstrates marked irregularity of the metaphysis in the distal femur and proximal tibia; the epiphyses are much less irregular. (c) The patient underwent hemiepiphyseal stapling for correcting genu valgum at the age of 9 . The genu valgum progressively corrected: (d), age 10 years; (e), age 11 years, but an important genu recurvatum was still evident on lateral weight-bearing radiograph (f).

\section{Pseudoachondroplasia}

Pseudoachondroplasia has an autosomal dominant inheritance. The age of presentation is the same as EDM (2-4 years, as the child starts to walk).

Subjects have a disproportionate short stature (arms appear long compared with torso), with normal facial features and head size. Intelligence is preserved. The fingers, wrists, elbows, and knees are markedly lax. Joint pain is a common complaint, and early onset of osteoarthritis involves every joint.

EDM and pseudoachondroplasia share many traits. Both are genotypic alleles (involving mutations of the same genes). ${ }^{67}$ However, clinical and radiologic manifestations are more severe in pseudoachondroplasia (- Fig. 7).

In the spine, the vertebrae have an oval shape, with a tongue-like projection in the anterior aspect that is patho- gnomonic of this entity but disappears over time with development of platyspondyly. As a result, the trunk is short.

Scoliosis, excessive kyphosis or lordosis, and cervical spine instability are seen as complications. The transient nature of the pathognomonic sign highlights the importance of obtaining radiographs early in this condition (-Fig. 8).

An important typical feature is joint-ligament laxity, to distinguish pseudoachondroplasia from other entities. The differential of pseudoachondroplasia includes EDM and achondroplasia. In EDM, there is no platyspondyly and doublelayered patella. Also, joints are not lax. In achondroplasia, there is no platyspondyly, the skull is abnormal, and only metaphyses are affected. The interpeduncular distance is decreased, and the hand and pelvis have typical appearances (trident hand, champagne glass pelvis). In pseudoachondroplasia, there is platyspondyly, epiphyses are involved, the skull is normal, and 
$\mathrm{a}, \mathrm{b}$
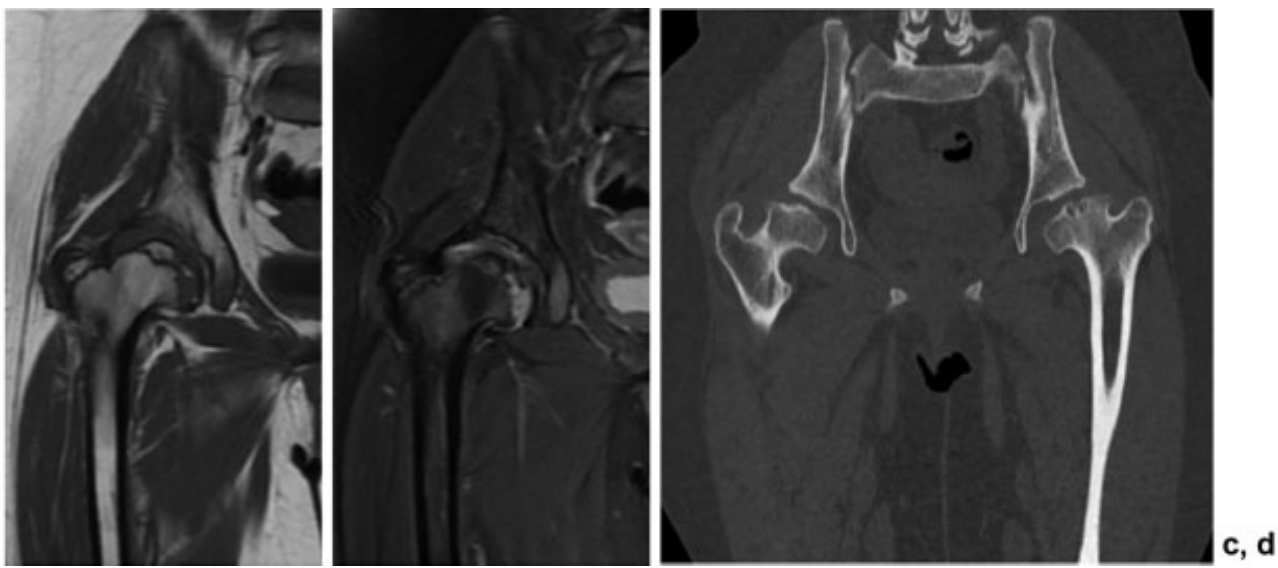

Fig. 5 Multiple epiphyseal dysplasia. (a) Weight-bearing anteroposterior radiograph of the lower limbs of an 11-year-old girl with bilateral and symmetrical irregularity of the epiphyses of the hips, knees, and ankles. Note the lateral tibiotalar inclination, with the lateral part of the distal tibial epiphysis thinner than the medial and the talus shaped to accommodate. (b) Detail of a coronal T1 image from magnetic resonance imaging performed at age 12 demonstrates marked irregularity of the epiphysis, with appearances that suggest fragmentation: patchy ossification. (c) On coronal proton-density fat sat image there is mild effusion, and the epiphyseal cartilage is inhomogeneous. (d) Coronal reconstruction from computed tomography at age 17 demonstrates the abnormal shape of the femoral heads (flattened) as well as a flat acetabulum. On the left, there is development of subchondral bone cysts as a sign of osteoarthritis.
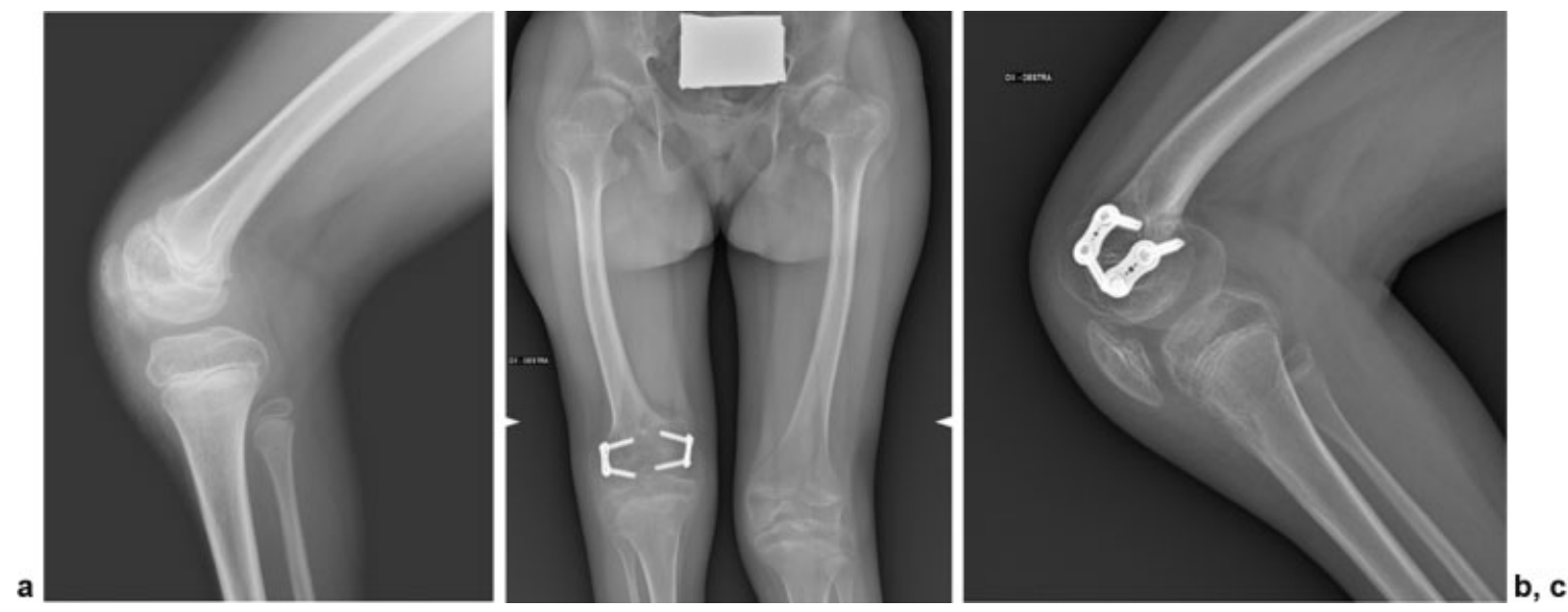

Fig. 6 Multiple epiphyseal dysplasia. (a) Lateral knee radiograph of a 7-year-old girl demonstrates pathognomonic appearances of a doublelayered patella. Progressive knee flexion deformity required correction at age 8 , with anterior epiphyseal stapling on the distal femur. Progressive contracture and deformity of the joints is a feature that differentiates multiple epiphyseal dysplasia from pseudoachondroplasia. Unfortunately, the stapling was unsuccessful. (b) Anteroposterior radiographs at age 10 demonstrate shortening of the femur. The marked irregularity of the femoral epiphyses is also noticeable. (c) Lateral view of the right knee better demonstrates the double-layered patella.

the specific abnormalities in the hand (trident hand) and pelvis (champagne pelvis) are not present.

\section{Mucopolysaccharidoses}

Mucopolysaccharidoses represent a group of storage disorders in which there are mutations in the genes that encode lysosomal enzymes with a role in the degradation of glycosaminoglycans (GAGs) or mucopolysaccharides. As a result, there is deposit of GAGs in various tissues. Typically, there is a coarse face, mental retardation, and hepatosplenomegaly.

Another name for these disorders is dysostoses multiplex because they are associated with multiple skeletal abnormalities.

If a mucopolysaccharidosis is suspected, the initial work-up includes urinalysis that will demonstrate elevated GAGs.
Studies of enzyme activity are performed in cultured fibroblasts or leucocytes.

Common features of mucopolysaccharidoses are epiphyseal abnormalities, pointed appearances of the base of the metacarpals, and beaking in the spine (inferior aspect of the bodies, with superior notching) (-Fig. 9). There are evolving joint contractures without inflammation. ${ }^{68}$ Osteoporosis is also seen.

Hurler's syndrome (mucopolysaccharidosis type I) is autosomal recessive in inheritance. Signs start to appear over the first 2 years of life. There is corneal clouding, coronary artery narrowing, endocardial fibroelastosis, and valvular disease. ${ }^{69}$ This translates into cardiomegaly on radiographs.

The head is large with frontal bossing. There is a "J-shaped" sella that occurs due to the deposit of GAGs in the pituitary gland. The ribs are broad anteriorly but thin posteriorly, with a 

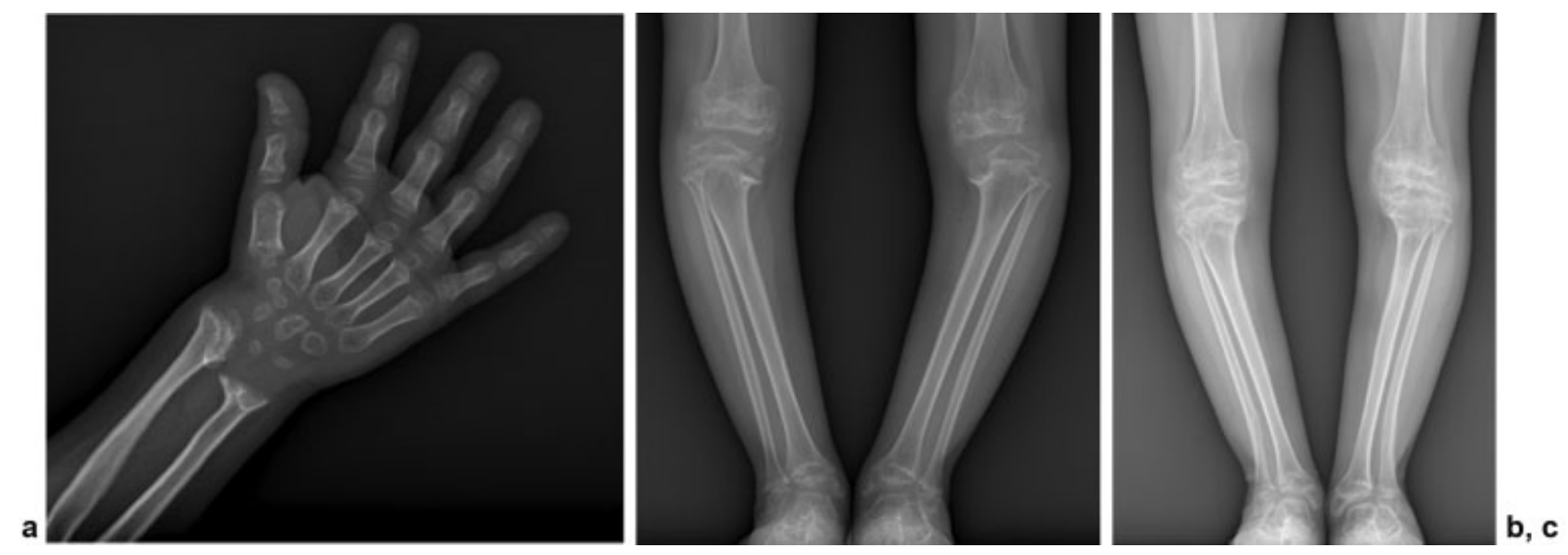

Fig. 7 Pseudoachondroplasia in a girl who presented at the age of 8. (a) Anteroposterior (AP) radiograph of the right hand demonstrates irregularity of the epiphysis of the radius and ulna, as well as brachydactyly that was seen to be symmetrical. (b) Detail of AP weight-bearing projection of the lower limbs at age 10 demonstrates irregularity of the epiphyses of the distal femur and proximal tibia. (c) There is genu varus that was corrected with bilateral high tibial osteotomies but unfortunately recurred on the right. Note that lateral tibiotalar inclination is seen in the ankle, a feature that may also be seen in multiple epiphyseal dysplasia that shares many traits with pseudoachondroplasia. The diagnosis of pseudoachondroplasia was confirmed by molecular investigation (COMP gene alteration).
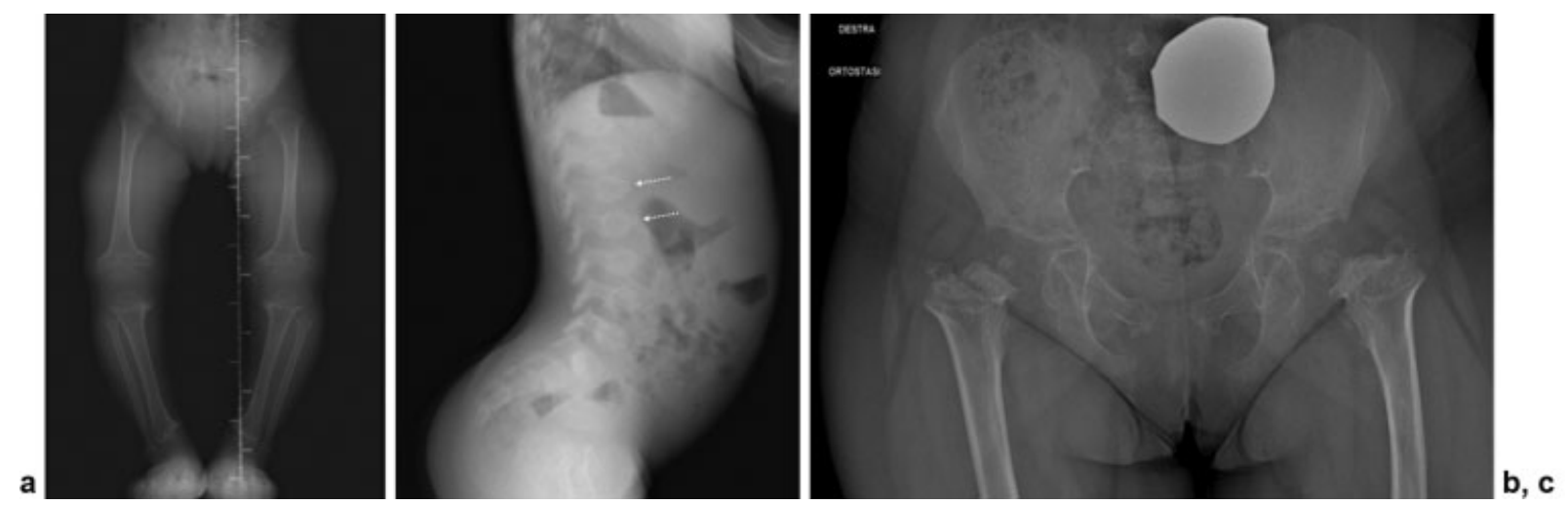

Fig. 8 Pseudoachondroplasia. (a) Anteroposterior (AP) radiograph of the lower legs in a 7-year-old girl demonstrates short long bones, predominantly rhizomelia. The metaphyses are irregular, but the epiphyses are as well, with lack of ossification of the proximal femoral epiphyses. There is irregularity of the distal femoral epiphyses and proximal tibial epiphyses. The distal tibial and fibular epiphyses are irregular. (b) In the lateral view of the spine, the vertebrae have a general oval shape, with a tongue-like projection in the anterior aspect that is pathognomonic of this entity (dotted arrows). (c) AP radiograph of the pelvis at age 11 demonstrates marked epiphyseal irregularity. This is a major difference with achondroplasia, in which epiphyses are not involved. Note as well the development of platyspondyly in the lower lumbar vertebral bodies and sacrum that does not occur in multiple epiphyseal dysplasia.

configuration that makes them resemble oars. The lateral ends of the clavicles are hypoplastic, with small scapulae. The length of the limbs is normal, but the diaphyses are widened, more so in the upper limbs. The distal radius and ulna may arch to converge.

In the hands, the tubular bones are normally short and wide, and the metacarpals are pointy at the base and broad at the head.

In the spine, L1 or L2 are hypoplastic and slightly misaligned, with the appearance of dorsolumbar kyphosis. There is also anteroinferior beaking, as mentioned. There is no platyspondyly. There can be atlantoaxial instability. The iliac wings are flared out, the acetabular roofs are shallow, and there is delayed ossification of the femoral heads. ${ }^{70}$

Morquio's syndrome (mucopolysaccharidosis type IV) is also autosomal recessive in inheritance. Pathologically, there is intracellular accumulation of keratan sulfate and chondroitin-6-sulfate.

In this case, there are dental abnormalities and corneal clouding with normal intelligence. ${ }^{71}$ The skull is enlarged, there is dorsolumbar kyphosis and atlantoaxial instability, with a normal sella, and there is platyspondyly, with central beaking.

In the hands, the typical pointy appearance of the metacarpal base is found, but additionally, there is irregular and delayed ossification of the carpal and tarsal bones. The epiphyses are enlarged, and the metaphyses widened, to accommodate. There is delayed ossification of the femoral heads, and as a consequence, the acetabula are poorly developed, leading to arthropathy. ${ }^{72}$

There is delayed ossification of the femoral heads, and as a consequence, the acetabula are poorly developed, leading to arthropathy. $^{72}$

Attenuated types of Morquio and type VI mucopolysaccharidosis have been described, in which involvement is limited to femoral heads. ${ }^{73,74}$

\section{Diastrophic Dysplasia}

Diastrophic dysplasia is characterized by scoliosis that results in short stature, bilateral clubfeet, premature 

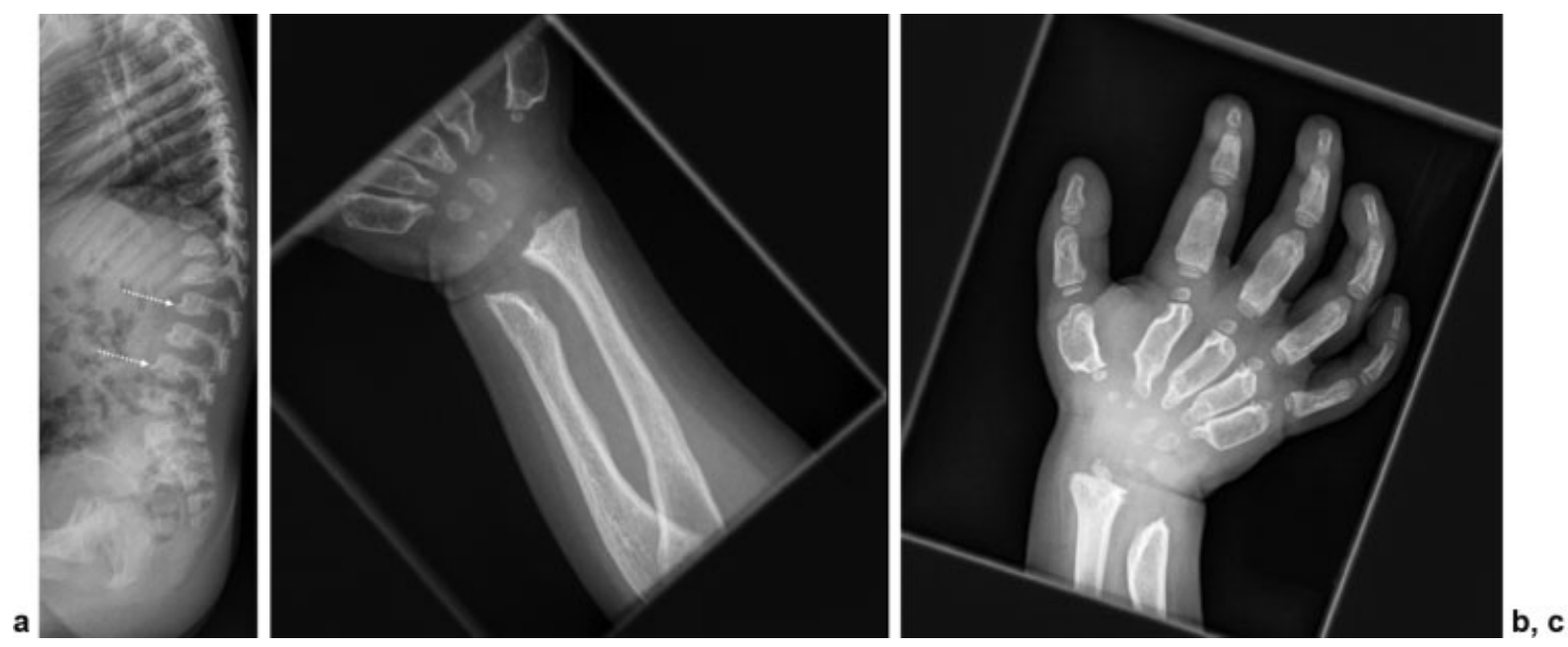

Fig. 9 Mucopolysaccharidosis. (a) Lateral spine radiograph in a 3-year-old boy with mucopolysaccharidosis type II-III, demonstrating "beaking" in the inferior aspect of the vertebral bodies, with superior notching (dotted arrows). (b) Left wrist anteroposterior radiograph demonstrates irregularity in the epiphyses of the radius and ulna, with slight arching of the distal ulna. (c) Radiograph of the right hand (age 4) demonstrates the typical appearances of the metacarpals that are pointy toward the base and broad distally. The epiphyseal abnormalities, pointed appearances of the base of the metacarpals and beaking in the spine, are common features of the different types of mucopolysaccharidoses.
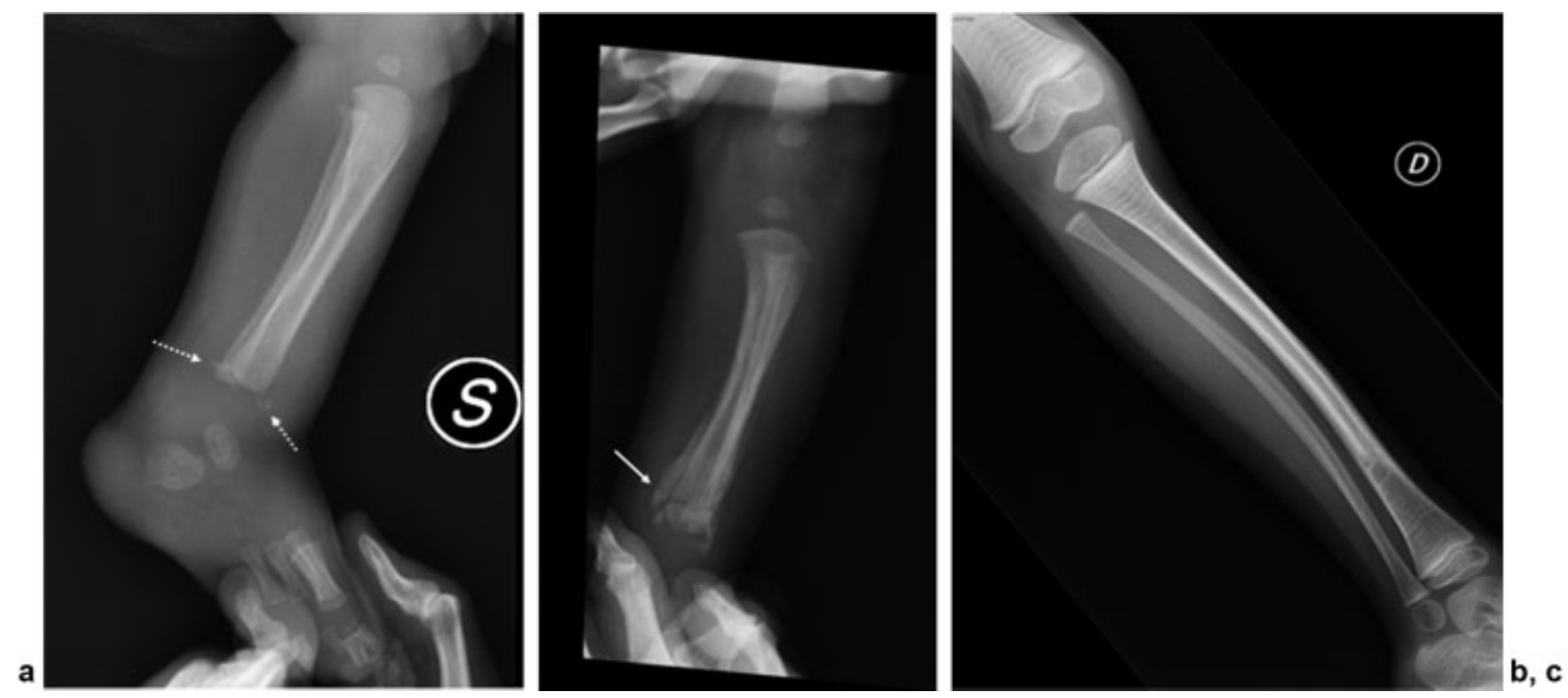

Fig. 10 Osteogenesis imperfecta type I. (a) Lateral radiograph of the left leg of a 3-week-old boy with osteogenesis imperfecta type I demonstrates small regions of early periosteal bone formation adjacent to the cortex of the distal metaphysis of the tibia (dotted arrows). (b) Weeks later (lateral radiograph), there is hypertrophic callus formation, with florid periosteal reaction, and a transverse lucent fracture line still visible through the distal tibia (arrow). The patient sustained multiple fractures of the tibias that were treated conservatively. He is on a background treatment of neridronate (bisphosphonate). (c) Anteroposterior radiograph of the leg of the same boy at age 6 demonstrates the typical "zebra lines" (band-like areas of increased opacity) seen in osteogenesis imperfecta patients treated with bisphosphonates. These are the result of failure of remodeling of the primary spongiosa into secondary spongiosa in the physis, associated with the cycles/doses of treatment. Note the decreased mineralization of the bone and the bowing of the tibia and fibula.

calcification of costal cartilages, occasional cleft palate, and a typical "hitchhiker thumb" appearance due to deformity of the first metacarpal. ${ }^{75}$ This is very characteristic and allows prenatal diagnosis. Historically, because of the findings, these patients were diagnosed with arthrogryposis (multiple contractures).

\section{Dysplasias with Altered Bone Density}

These dysplasias are genetically heterogeneous, caused by multiple mutations. Due to the genetic complexity, the focus is on the clinical manifestations to reach a prognosis.
The prototype of reduced bone density is osteogenesis imperfecta. There are other syndromes, labeled as syndromes, with congenital brittle bones that also show decreased bone density.

The prototype of increased bone density is osteopetrosis, but osteosclerotic dysplasias may be further classified into three groups, with endochondral bone formation, such as osteopetrosis, pyknodysostosis, bone island, osteopoikilosis and osteopathia striata, intramembranous bone formation, like progressive diaphyseal dysplasia (Camurati-Engelmann's disease), Caffey's disease, and mixed sclerosing, such as melorheostosis and overlap syndromes. 
a, b
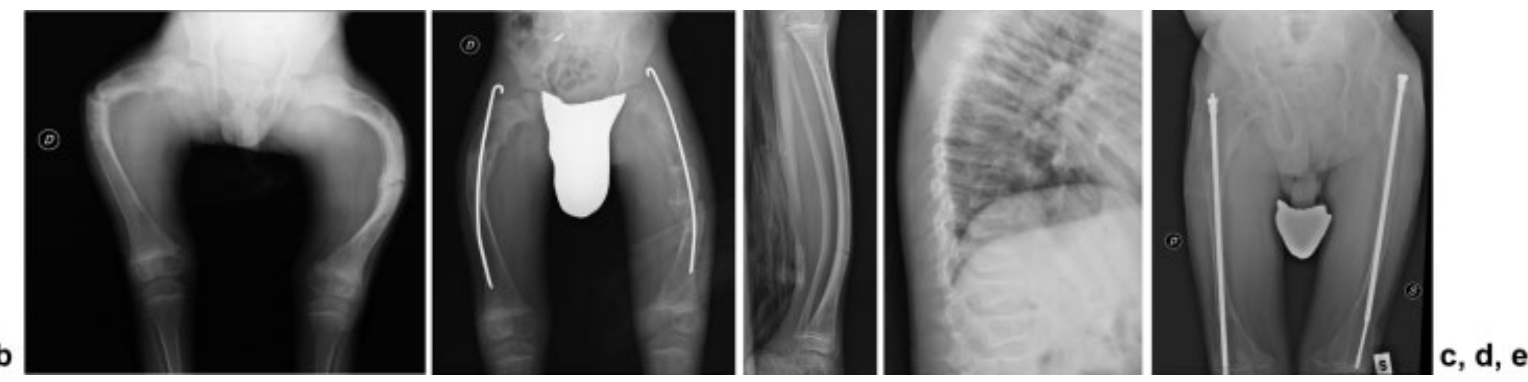

Fig. 11 Osteogenesis imperfecta type III. (a) Anteroposterior (AP) radiograph of the hips and femurs of a 5-year-old boy, with typical "shepherd's crook" deformity in both femurs and bilateral fractures (right, proximal femur and left, mid aspect). There is callus formation associated with these fractures. Note the generalized decreased bone mineralization. (b) The fractures were fixated and the excessive varus deformity corrected with osteotomies and intramedullary K-wires. (c) Not long after the surgery (still age 5) the boy sustained a fracture of the distal right tibia. There is marked bowing of the tibia and fibula, and decreased bone density. (d) Lateral radiograph of the spine at age 8 demonstrates severe loss of height of all vertebral bodies, which either have a biconcave or a wedge-shaped configuration, with generalized demineralization. (e) AP radiograph of hips and femurs at age 14. Note the severe demineralization. There is marked right protrusio acetabuli and dislocation of the left hip, with deformity of the proximal femur; neck and femoral head are absent. Fractures to the femurs and tibias were recurrent, treated with multiple multifocal femoral and tibial osteotomies and intramedullary nailing (e, Fassier-Duval telescopic nail).

\section{Osteogenesis Imperfecta}

In osteogenesis imperfecta, inheritance is variable, autosomal dominant or recessive. The disorder is due to a mutation in type I procollagen genes. There is decreased bone mass and bone fragility, as a consequence.

Extraskeletal manifestations include blue sclerae, dentinogenesis imperfecta, and deafness.

The severity is variable, and there are eight types. Type II, for example, is lethal perinatally. In order of severity, VIII, III (progressively deforming), VII, VI, V, and IV follow. ${ }^{76}$ Type I is the less severe type (-Fig. 10).

Typical radiologic features are diffuse osteopenia, with very thin cortices and multiple fractures. Healing of these fractures occurs with exuberant callus ("pseudotumor"). There may be deformities and pseudoarthrosis. Vertebrae are also osteopenic, and collapse, with biconcave appearances. In the skull, there are multiple wormian bones, the calvarium is lucent, sinuses are enlarged, and there is platybasia (flattening of the skull base). In the pelvis, protrusio acetabuli is common. The femur has the typical appearance of a "shepherd's crook" ( - Fig. 11).

In the differential, nonaccidental injuries have to be considered. Other entities with decreased bone density are hypophosphatasia, juvenile idiopathic osteoporosis, and other syndromes with congenital brittle bones ${ }^{77}$ that are labeled as syndromes resembling osteogenesis imperfecta. In the latter, mutations do not involve the type I procollagen genes.

\section{Osteopetrosis}

In osteopetrosis, there is failure of normal osteoclastic resorption of bone. The result is increased density in the medullary portions of the bones. Cortices are spared. ${ }^{78}$

There is a also lot of genetic heterogenicity, as well as clinical presentations. The most severe type is recessive, of early onset, and causes bone marrow failure, with progressive alterations in the blood cell counts (due to the obliteration of the medullary canals) and early death.

In the skull, there is diffuse sclerosis that involves the base and vault. There is progressive narrowing of the foramina at the base that causes cranial nerve impingement and related symptoms. The mandible is prognathic.
Mandibular osteomyelitis incidence is increased. In the limbs, there is also diffuse sclerosis and metaphyseal flaring ("Erlenmeyer flask deformity") ${ }^{79}$ with a high incidence of fractures. Healing is normal, but callus formation is defective.

There is also a "bone within bone" appearance, seen in the spine, pelvis, and short tubular bones. In the spine, vertebrae have "sandwich" appearances, due to end-plate sclerosis. In the pelvis, there are multiple sclerotic lines parallel to the iliac crest.

A group of entities, the craniotubular dysplasias, resemble osteopetrosis and pose a challenge in differential diagnosis. They have similar cranial and metaphyseal features. ${ }^{80}$ The involvement of tubular bones is different, vertebrae are normal, and there is no disturbance to hematopoiesis, features that can help with distinction.

\section{Pycnodysostosis}

Pycnodysostosis is a condition with autosomal recessive inheritance that presents in early childhood, with a triad of increased bone density, fractures, and dwarfism with short limbs. ${ }^{81}$

The skull demonstrates base and vault sclerosis, with open sutures and fontanelles and multiple wormian bones. There is mandibular hypoplasia.

In the limbs, there is sclerosis of long bones. Limb length is decreased. The pelvis is sclerotic, with small and shallow acetabulum.

Acro-osteolysis is seen in the hands. The medullary cavity is maintained, and there may be an associated Madelung's deformity.

The main differential is osteopetrosis, and distinction may be made by the appearances of the skull with open sutures, the small mandible, and the acro-osteolysis. ${ }^{78}$

\section{Osteopoikilosis}

Osteopoikilosis is of autosomal dominant inheritance, more common in males, and benign. The typical features are multiple small $(1-10 \mathrm{~mm})$ dense concretions at the end of the long bones often just deep to the cortex, in the carpal and 

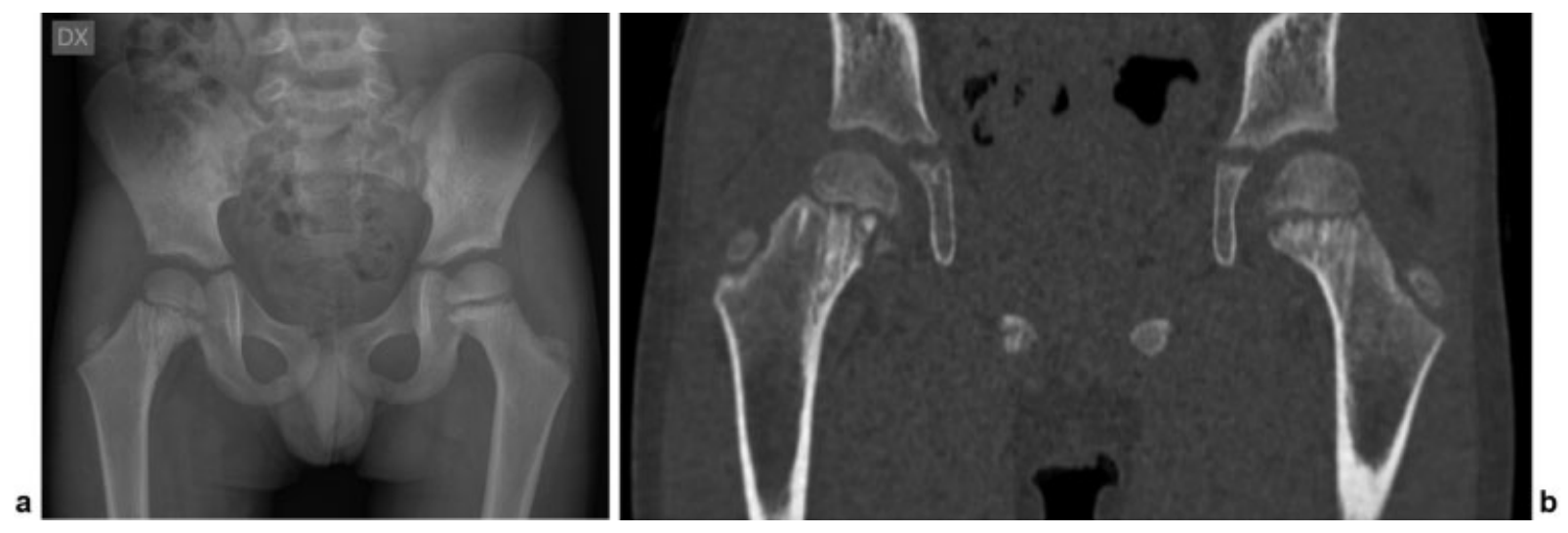

Fig. 12 Osteopathia striata. (a) Anteroposterior radiograph of the pelvis in a 5-year-old boy. Typical appearances of multiple thin vertical sclerotic lines in the proximal metaphysis of the femur that extend into the diaphysis. (b) Note the slight irregularity in the metaphysis, more evident on coronal computed tomography image.

tarsal bones, in a periacetabular location and in the subglenoid area. ${ }^{82}$ These are symmetrical and uniform. These concretions represent multiple benign enostoses.

The condition is asymptomatic, incidentally found in radiographs. The enostoses appear during childhood and do not regress with adulthood. In adulthood, they may be mistaken by other entities such as metastases, hence the importance of accurate diagnosis.

Osteopoikilosis is often found with osteopathia striata and melorheostosis, probably representing a spectrum of the same condition, also called mixed sclerosing bone dysplasia, due to a mutation of the LEMD3 gene. ${ }^{83}$

The association of osteopoikilosis with disseminated connective tissue and cutaneous nevi, on extremities and trunk, that have a yellowish shade is known as Buschke-Ollendorff syndrome (disseminated dermatofibrosis lenticularis). ${ }^{84}$

\section{Osteopathia Striata}

The typical form of osteopathia striata is also known as Voorhoeve's disease and is benign, characteristically involving the epiphysis and metaphysis of tubular bones, happening in any age group.

The condition is usually asymptomatic, although some patients describe joint discomfort. There is bilateral involvement of long bones, pelvis, and scapulae, with multiple thin vertical sclerotic lines in the metaphysis, extending into the diaphysis $^{78}$ (-Fig. 12).

Osteopathia striata may be found associated with cutaneous manifestations, such as hypopigmented or hyperpigmented lesions, known as Goltz's syndrome or focal dermal hypoplasia. ${ }^{85}$ This disorder follows an X-linked dominant inheritance pattern and is more commonly seen in males.

Osteopathia striata with cranial sclerosis is a different clinical entity that is very rare.

This condition is of X-linked dominant inheritance, more common in females, and more severe and with higher mortality in males. ${ }^{86}$ The condition affects multiple systems.

There may be sclerosis of the long bones and the skull, with cranial nerve compression, and there are cases of cleft palate. ${ }^{87}$

\section{Progressive Diaphyseal Dysplasia}

Progressive diaphyseal dysplasia is of autosomal dominant inheritance and also called Camurati-Engelmann's disease. The hallmark of the disease is increased bone density, affecting the tibia, femur, humerus, ulna, and radius. In some cases, pelvis and skull are also affected.

Patients develop pain, a waddling gait, muscle weakness, and limiting tiredness.

Neurologic problems caused by increased intracranial pressure and cranial nerve compromise may also be seen, such as headaches, visual and hearing loss, vertigo, tinnitus, and facial palsy. Scoliosis, contractures, and valgum of the knees and pes planus may also be present. ${ }^{82,88}$

Radiographically, there is bilateral symmetrical enlargement, with increased density of the diaphysis of the long bones that begins in the midportion and extends in a fusiform shape toward both ends. Metaphyses may be involved, but typically, epiphyses are not. ${ }^{82,88}$

\section{Caffey's Disease}

Caffrey's disease is an autosomal inherited condition (dominant and recessive forms) that presents early in life (before the fifth month), with hyperirritability, soft tissue swelling, bone lesions, and typical mandible involvement. Acute manifestations are inflammatory, with fever and hot, tender swelling. ${ }^{89}$

The ulna, tibia, clavicle scapulae, and ribs may also be involved.

Radiologically, there is diffuse cortical thickening, due to subperiosteal new bone formation that typically involves the diaphysis, sparing metaphyses and epiphyses (-Fig. 13).

The condition usually resolves spontaneously by 2 years of age. Despite its appearances in acute stages, the bones return to completely normal in subsequent studies.

\section{Melorheostosis}

Melorheostosis may present sporadically or be inherited. It is a benign condition with pain and soft tissue contractures as clinical features.

Radiologically, there is cortical thickening, in a wavy, characteristic pattern, a "flowing wax candle" appearance. 

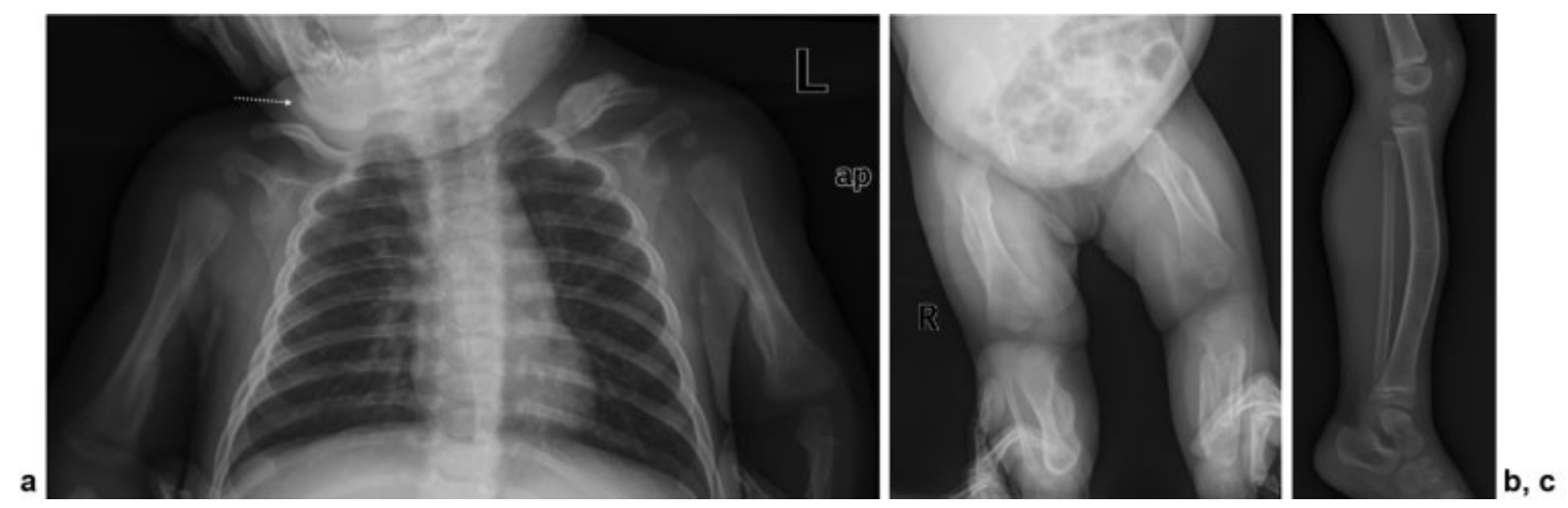

Fig. 13 Caffey's disease. A 2-month-old girl presented with hyperirritability, fever, and regions of soft tissue swelling with inflammatory signs. (a) Anteroposterior (AP) chest radiograph demonstrates diffuse cortical thickening in both humeri, left clavicle, and in the mandible (dotted arrow). Mandible involvement is typical of Caffey's disease. (b) AP radiograph of the lower limbs shows similar diffuse cortical thickening involving the femurs and tibias, due to subperiosteal new bone formation. Caffey's disease was confirmed by molecular investigation, inherited from the mother. (c) At age 3, there is complete resolution of the cortical thickening and deformities, with mild residual bowing of the tibias (lateral view of the right tibia shown).

a, a
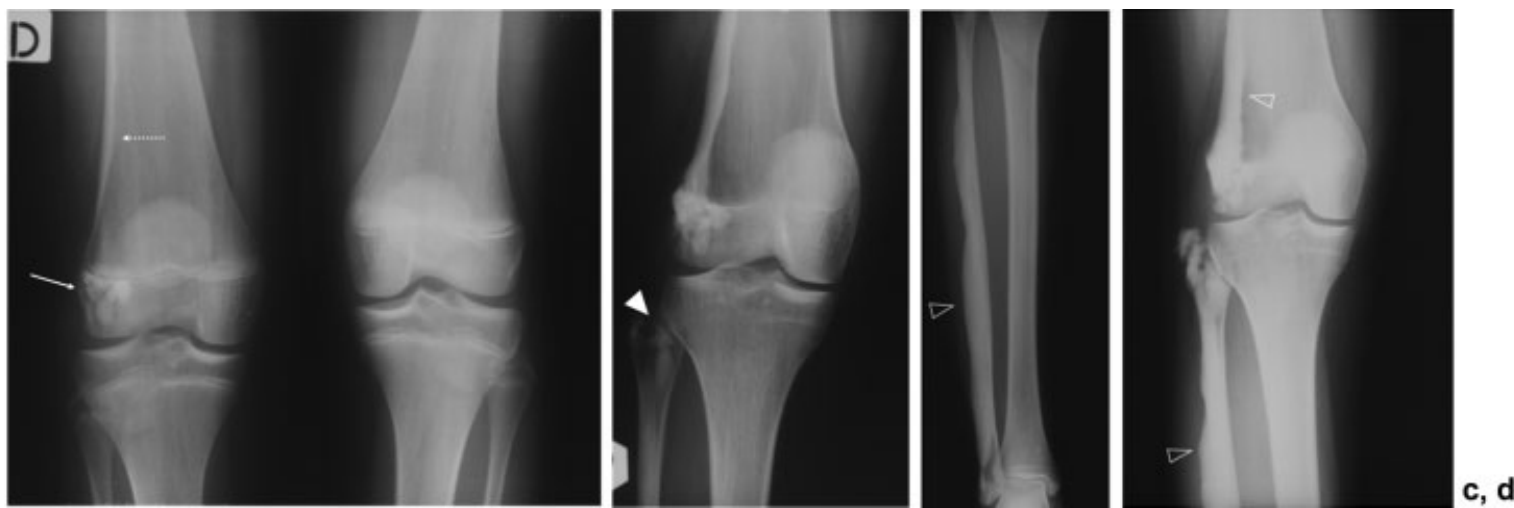

Fig. 14 Melorheostosis. (a) Anteroposterior (AP) radiograph of the knees of a 12-year-old girl, with typical features of cortical thickening, which is subtle, endosteal (dotted arrow), in the lateral aspect of the distal right femur. There is also a sclerotic region with lobulated contours (arrow) in the lateral aspect of the distal femoral epiphysis. (b) AP radiograph of the right knee at age 17 demonstrates progression of the cortical thickening, which is mainly endosteal, and displays a mildly wavy contour. The thickening extends to the epiphysis, where it becomes confluent with the sclerotic region in the lateral aspect of the epiphysis. Regions of cortical thickening have also become apparent in the proximal fibula (bold arrowhead). (c) AP radiograph of the leg at age 19 shows general cortical thickening in the fibula, with wavy contours, the typical "flowing wax candle" appearances (arrowhead). The thickening is periosteal. (d) AP radiograph of the knee at age 22 demonstrates generalized progression of the cortical thickening (arrowheads). Distribution is asymmetric and can be monostotic or polyostotic or monomelic. If monomelic, it typically involves the lower limb, as in this case. The diagnosis was confirmed by clinical and radiographic findings, even though the molecular tests (LEMD3) were negative.

Distribution is asymmetric and can be mono- or polyostotic or monomelic. If monomelic, it typically involves the lower limb. Other bones like the skull, ribs, spine, and short tubular bones are occasionally affected. In children, the pattern of involvement is endosteal, and in adults, perioste$\mathrm{al}^{82}$ (- Fig. 14).

Melorheostosis may be found with osteopoikilosis and osteopathia striata, probably representing a spectrum of the same condition called mixed sclerosing bone dysplasia, due to a mutation of the LEMD3 gene. ${ }^{83}$

\section{Conclusion}

The diagnosis of the most severe congenital abnormalities of the skeletal system is normally done prenatally, but in the cases of nonlethal dysplasias, manifestations will only appear later, and the diagnosis will be achieved from the evaluation of clinical and family history, physical examination, radiologic assessment, and molecular/biochemical tests.

Radiographic evaluation is a fundamental part of the diagnostic work-up of congenital skeletal disorders, and in most cases it is the first tool to orient a diagnosis.

This review has described the imaging characteristics, specific signs, and evolution in several skeletal dysplasias in which diagnosis may be oriented or directly suggested by radiologic findings. We based our review of imaging findings on anatomical involvement, at the general and bone level, and intrinsic bone characteristics.

Definitive diagnosis of congenital skeletal abnormalities is necessary to enable the pediatrician and geneticist to offer a prognosis in terms of expected outcomes in adulthood, and to counsel parents and patients.

\section{Conflict of Interest}

None declared. 


\section{References}

1 Hall CM. International nosology and classification of constitutional disorders of bone (2001). Am J Med Genet 2002;113(01):65-77

2 Offiah AC, Hall CM. Radiological diagnosis of the constitutional disorders of bone. As easy as A, B, C? Pediatr Radiol 2003;33(03):153-161

3 Warman ML, Cormier-Daire V, Hall C, et al. Nosology and classification of genetic skeletal disorders: 2010 revision. Am J Med Genet A 2011;155A(05):943-968

4 Mortier GR, Cohn DH, Cormier-Daire V, et al. Nosology and classification of genetic skeletal disorders: 2019 revision. Am J Med Genet A 2019;179(12):2393-2419

5 Orioli IM, Castilla EE, Barbosa-Neto JG. The birth prevalence rates for the skeletal dysplasias. J Med Genet 1986;23(04):328-332

6 Andersen PE Jr, Hauge M. Congenital generalised bone dysplasias: a clinical, radiological, and epidemiological survey. J Med Genet 1989;26(01):37-44

7 Bonafe L, Cormier-Daire V, Hall C, et al. Nosology and classification of genetic skeletal disorders: 2015 revision. Am J Med Genet A 2015;167A(12):2869-2892

8 Calder AD, Offiah AC. Foetal radiography for suspected skeletal dysplasia: technique, normal appearances, diagnostic approach. Pediatr Radiol 2015;45(04):536-548

9 Chitty LS, Altman DG. Charts of fetal size: limb bones. BJOG 2002; 109(08):919-929

10 Olsen BR, Reginato AM, Wang W. Bone development. Annu Rev Cell Dev Biol 2000;16:191-220

11 van Zalen-Sprock RM, Brons JT, van Vugt JM, van der Harten HJ, van Geijn HP. Ultrasonographic and radiologic visualization of the developing embryonic skeleton. Ultrasound Obstet Gynecol 1997; 9(06):392-397

12 Altman DG, Chitty LS. Charts of fetal size: 1 . Methodology. Br J Obstet Gynaecol 1994;101(01):29-34

13 Exacoustos C, Rosati P, Rizzo G, Arduini D. Ultrasound measurements of fetal limb bones. Ultrasound Obstet Gynecol 1991;1(05): 325-330

14 Chitty LS, Altman DG, Henderson A, Campbell S. Charts of fetal size: 4. Femur length. Br J Obstet Gynaecol 1994;101(02):132-135

15 Krakow D, Lachman RS, Rimoin DL. Guidelines for the prenatal diagnosis of fetal skeletal dysplasias. Genet Med 2009;11(02): 127-133

16 Pilu G, Nicolaides KH. Diagnosis of Fetal Abnormalities: The 18-23Week Scan. Nashville, TN: Parthenon Publication Group; 1999

17 Yoshimura S, Masuzaki H, Gotoh H, Fukuda H, Ishimaru T. Ultrasonographic prediction of lethal pulmonary hypoplasia: comparison of eight different ultrasonographic parameters. Am J Obstet Gynecol 1996;175(02):477-483

18 Rahemtullah A, McGillivray B, Wilson RD. Suspected skeletal dysplasias: femur length to abdominal circumference ratio can be used in ultrasonographic prediction of fetal outcome. Am J Obstet Gynecol 1997;177(04):864-869

19 Gaffney G, Manning N, Boyd PA, Rai V, Gould S, Chamberlain P. Prenatal sonographic diagnosis of skeletal dysplasias-a report of the diagnostic and prognostic accuracy in 35 cases. Prenat Diagn 1998;18(04):357-362

20 Savarirayan R, Rossiter JP, Hoover-Fong JE, et al;Skeletal Dysplasia Management Consortium. Best practice guidelines regarding prenatal evaluation and delivery of patients with skeletal dysplasia. Am J Obstet Gynecol 2018;219(06):545-562

21 Parilla BV, Leeth EA, Kambich MP, Chilis P, MacGregor SN. Antenatal detection of skeletal dysplasias. J Ultrasound Med 2003;22 (03):255-258; quiz 259-261

22 Doray B, Favre R, Viville B, Langer B, Dreyfus M, Stoll C. Prenatal sonographic diagnosis of skeletal dysplasias. A report of 47 cases. Ann Genet 2000;43(3-4):163-169

23 Eckalbar WL, Fisher RE, Rawls A, Kusumi K. Scoliosis and segmentation defects of the vertebrae. Wiley Interdiscip Rev Dev Biol 2012;1(03):401-423
24 Adler-Levy Y, Yagel S, Nadjari M, Bar-ziv Y, Simanovsky N, Hiller N. Use of low dose computed tomography with 3D reconstructions for the prenatal evaluation of suspected skeletal dysplasia. Isr Med Assoc J 2015;17(01):42-46

25 Victoria T, Epelman M, Bebbington M, et al. Low-dose fetal CT for evaluation of severe congenital skeletal anomalies: preliminary experience. Pediatr Radiol 2012;42(Suppl 1):S142-S149

26 Victoria T, Zhu X, Lachman R, et al. What is new in prenatal skeletal dysplasias? AJR Am J Roentgenol 2018;210(05):1022-1033

27 Imai R, Miyazaki O, Horiuchi T, et al. Ultra-low-dose fetal CT with model-based iterative reconstruction: a prospective pilot study. AJR Am J Roentgenol 2017;208(06):1365-1372

28 Cassart M, Massez A, Cos T, et al. Contribution of three-dimensional computed tomography in the assessment of fetal skeletal dysplasia. Ultrasound Obstet Gynecol 2007;29(05):537-543

29 Ruano R, Molho M, Roume J, Ville Y. Prenatal diagnosis of fetal skeletal dysplasias by combining two-dimensional and threedimensional ultrasound and intrauterine three-dimensional helical computer tomography. Ultrasound Obstet Gynecol 2004;24 (02):134-140

30 Miyazaki O, Nishimura G, Sago H, Horiuchi T, Hayashi S, Kosaki R. Prenatal diagnosis of fetal skeletal dysplasia with 3D CT. Pediatr Radiol 2012;42(07):842-852

31 ACOG Committee Opinion \#299: Guidelines for Diagnostic Imaging During Pregnancy. Obstet Gynecol 2004;104(03):647

32 McCollough CH, Schueler BA, Atwell TD, et al. Radiation exposure and pregnancy: when should we be concerned? Radiographics 2007;27(04):909-917; discussion 917-918

33 Valentin J. Editorial: BACK TO BASICS. Ann ICRP 2000;30(01): iii-iv

34 Dighe M, Fligner C, Cheng E, Warren B, Dubinsky T. Fetal skeletal dysplasia: an approach to diagnosis with illustrative cases. Radiographics 2008;28(04):1061-1077

35 Mazzanti L, Matteucci C, Scarano E, Tamburrino F, Ragni MC, Cicognani A. Auxological and anthropometric evaluation in skeletal dysplasias. J Endocrinol Invest 2010;33(6, Suppl):19-25

36 Kozlowski K. The radiographic clues in the diagnosis of bone dysplasias. Pediatr Radiol 1985;15(01):1-3

37 Bellus GA, Hefferon TW, Ortiz de Luna RI, et al. Achondroplasia is defined by recurrent G380R mutations of FGFR3. Am J Hum Genet 1995;56(02):368-373

38 Langer LO Jr, Baumann PA, Gorlin RJ. Achondroplasia. Am J Roentgenol Radium Ther Nucl Med 1967;100(01):12-26

39 Bellus GA, McIntosh I, Smith EA, et al. A recurrent mutation in the tyrosine kinase domain of fibroblast growth factor receptor 3 causes hypochondroplasia. Nat Genet 1995;10(03):357-359

40 Song S-H, Balce GCE, Agashe MV, et al. New proposed clinicoradiologic and molecular criteria in hypochondroplasia: FGFR 3 gene mutations are not the only cause of hypochondroplasia. Am J Med Genet A 2012;158A(10):2456-2462

41 Bober MB, Bellus GA, Nikkel SM, Tiller GE. Hypochondroplasia. In: Adam MP, Ardinger HH, Pagon RA, et al., eds. GeneReviews. University of WashingtonSeattle1993www.ncbi.nlm.nih.gov/ books/NBK1477/. Accessed November 26, 2020

42 Hall BD, Spranger J. Hypochondroplasia: clinical and radiological aspects in 39 cases. Radiology 1979;133(01):95-100

43 Polymeropoulos MH, Ide SE, Wright M, et al. The gene for the Ellisvan Creveld syndrome is located on chromosome $4 \mathrm{p} 16$. Genomics 1996;35(01):1-5

44 Ruiz-Perez VL, Ide SE, Strom TM, et al. Mutations in a new gene in Ellis-van Creveld syndrome and Weyers acrodental dysostosis. Nat Genet 2000;24(03):283-286

45 Hills CB, Kochilas L, Schimmenti LA, Moller JH. Ellis-van Creveld syndrome and congenital heart defects: presentation of an additional 32 cases. Pediatr Cardiol 2011;32(07):977-982

46 Rudnik-Schöneborn S, Zerres K, Graul-Neumann L, Wiegand S, Mellerowicz H, Hehr U. Two adult patients with Ellis-van Creveld 
syndrome extending the clinical spectrum. Mol Syndromol 2011; 1(06):301-306

47 Happle R, Matthiass HH, Macher E. Sex-linked chondrodysplasia punctata? Clin Genet 1977;11(01):73-76

48 Manzke H, Christophers E, Wiedemann HR. Dominant sex-linked inherited chondrodysplasia punctata: a distinct type of chondrodysplasia punctata. Clin Genet 1980;17(02):97-107

49 Wanders RJA, Waterham HR. Peroxisomal disorders I: biochemistry and genetics of peroxisome biogenesis disorders. Clin Genet 2005;67(02):107-133

50 Zizka J, Charvat J, Baxova A, Balicek P, Kozlowski K. Brachytelephalangic chondrodysplasia punctata with distinctive phenotype and normal karyotype. Am J Med Genet 1998;76(03):213-216

51 Shanske AL, Bernstein L, Herzog R. Chondrodysplasia punctata and maternal autoimmune disease: a new case and review of the literature. Pediatrics 2007;120(02):e436-e441

52 Anderson IJ, Goldberg RB, Marion RW, Upholt WB, Tsipouras P. Spondyloepiphyseal dysplasia congenita: genetic linkage to type II collagen (COL2AI). Am J Hum Genet 1990;46(05):896-901

53 Veeravagu A, Lad SP, Camara-Quintana JQ Jiang B, Shuer L. Neurosurgical interventions for spondyloepiphyseal dysplasia congenita: clinical presentation and assessment of the literature. World Neurosurg 2013;80(3-4):437.e1-437.e8

54 MacKenzie JJ, Fitzpatrick J, Babyn P, et al. X linked spondyloepiphyseal dysplasia: a clinical, radiological, and molecular study of a large kindred. J Med Genet 1996;33(10):823-828

55 Leroy JG, Leroy BP, Emmery LV, Messiaen L, Spranger JW. A new type of autosomal recessive spondyloepiphyseal dysplasia tarda. Am J Med Genet A 2004;125A(01):49-56

56 Wilkin DJ, Artz AS, South S, et al. Small deletions in the type Il collagen triple helix produce Kniest dysplasia. Am J Med Genet 1999;85(02):105-112

57 Subramanian S, Gamanagatti S, Sinha A, Sampangi R. Kniest syndrome. Indian Pediatr 2007;44(12):931-933

58 Borochowitz Z, Lachman R, Adomian GE, Spear G, Jones K, Rimoin DL. Achondrogenesis type I: delineation of further heterogeneity and identification of two distinct subgroups. J Pediatr 1988;112 (01):23-31

59 Langer LO Jr, Spranger JW, Greinacher I, Herdman RC. Thanatophoric dwarfism. A condition confused with achondroplasia in the neonate, with brief comments on achondrogenesis and homozygous achondroplasia. Radiology 1969;92(02):285-294, passim

60 Murray LW, Rimoin DL. Abnormal type II collagen in the spondyloepiphyseal dysplasias. Pathol Immunopathol Res 1988;7(1-2):99-103

61 Tiller GE, Polumbo PA, Weis MA, et al. Dominant mutations in the type II collagen gene, COL2A1, produce spondyloepimetaphyseal dysplasia, Strudwick type. Nat Genet 1995;11(01):87-89

62 Anderson CE, Sillence DO, Lachman RS, et al. Spondylometepiphyseal dysplasia, Strudwick type. Am J Med Genet 1982;13(03): 243-256

63 Briggs MD, Hoffman SM, King LM, et al. Pseudoachondroplasia and multiple epiphyseal dysplasia due to mutations in the cartilage oligomeric matrix protein gene. Nat Genet 1995;10(03):330-336

64 Ramachandran G, Mason D. Double-layered patella: marker for multiple epiphyseal dysplasia. Am J Orthop 2004;33(01):35-36

65 Sheffield EG. Double-layered patella in multiple epiphyseal dysplasia: a valuable clue in the diagnosis. J Pediatr Orthop 1998;18 (01):123-128

66 Vatanavicharn N, Lachman RS, Rimoin DL. Multilayered patella: similar radiographic findings in pseudoachondroplasia and recessive multiple epiphyseal dysplasia. Am J Med Genet A 2008; 146A(13):1682-1686

67 Briggs MD, Chapman KL. Pseudoachondroplasia and multiple epiphyseal dysplasia: mutation review, molecular interactions, and genotype to phenotype correlations. Hum Mutat 2002;19 (05):465-478

68 Lachman R, Martin KW, Castro S, Basto MA, Adams A, Teles EL. Radiologic and neuroradiologic findings in the mucopolysaccharidoses. J Pediatr Rehabil Med 2010;3(02):109-118

69 Schroeder L, Orchard P, Whitley CB, et al. Cardiac ultrasound findings in infants with severe (Hurler phenotype) untreated mucopolysaccharidosis (MPS) type I. JIMD Rep 2013;10:87-94

70 Cleary MA, Wraith JE. The presenting features of mucopolysaccharidosis type IH (Hurler syndrome). Acta Paediatr 1995;84(03): 337-339

71 Montaño AM, Tomatsu S, Brusius A, Smith M, Orii T. Growth charts for patients affected with Morquio A disease. Am J Med Genet A 2008;146A(10):1286-1295

72 Hendriksz CJ, Harmatz P, Beck M, et al. Review of clinical presentation and diagnosis of mucopolysaccharidosis IVA. Mol Genet Metab 2013;110(1-2):54-64

73 Hecht JT, Scott CI Jr, Smith TK, Williams JC. Mild manifestations of the Morquio syndrome. Am J Med Genet 1984;18(02):369-371

74 Lachman RS, Burton BK, Clarke LA, et al. Mucopolysaccharidosis IVA (Morquio A syndrome) and VI (Maroteaux-Lamy syndrome): under-recognized and challenging to diagnose. Skeletal Radiol 2014;43(03):359-369

75 Gembruch U, Niesen M, Kehrberg H, Hansmann M. Diastrophic dysplasia: a specific prenatal diagnosis by ultrasound. Prenat Diagn 1988;8(07):539-545

76 Rauch F, Glorieux FH. Osteogenesis imperfecta. Lancet 2004;363 (9418):1377-1385

77 Plotkin H. Syndromes with congenital brittle bones. BMC Pediatr 2004;4(01):16

78 Vanhoenacker FM, De Beuckeleer LH, Van Hul W, et al. Sclerosing bone dysplasias: genetic and radioclinical features. Eur Radiol 2000;10(09):1423-1433

79 Faden MA, Krakow D, Ezgu F, Rimoin DL, Lachman RS. The Erlenmeyer flask bone deformity in the skeletal dysplasias. Am J Med Genet A 2009;149A(06):1334-1345

80 Brueton LA, Winter RM. Craniodiaphyseal dysplasia. J Med Genet 1990;27(11):701-706

81 Maroteaux P, Lamy M. Pyknodysostosis. [in French]. Presse Med 1962;70:999-1002

82 Ihde LL, Forrester DM, Gottsegen CJ, et al. Sclerosing bone dysplasias: review and differentiation from other causes of osteosclerosis. Radiographics 2011;31(07):1865-1882

83 Benli IT, Akalin S, Boysan E, Mumcu EF, Kiş M, Türkoğlu D. Epidemiological, clinical and radiological aspects of osteopoikilosis. J Bone Joint Surg Br 1992;74(04):504-506

84 Bansal A. The dripping candle wax sign. Radiology 2008;246(02): 638-640

85 Goltz RW, Peterson WC, Gorlin RJ, Ravits HG. Focal dermal hypoplasia. Arch Dermatol 1962;86(06):708-717

86 Behninger C, Rott HD. Osteopathia striata with cranial sclerosis: literature reappraisal argues for X-linked inheritance. Genet Couns 2000;11(02):157-167

87 Winter RM, Crawfurd Md'A, Meire HB, Mitchell N. Osteopathia striata with cranial sclerosis: highly variable expression within a family including cleft palate in two neonatal cases. Clin Genet 1980;18(06):462-474

88 Janssens K, Vanhoenacker F, Bonduelle M, et al. Camurati-Engelmann disease: review of the clinical, radiological, and molecular data of 24 families and implications for diagnosis and treatment. J Med Genet 2006;43(01):1-11

89 Pickering D, Cuddigan B. Infantile cortical hyperostosis associated with thrombocythaemia. Lancet 1969;2(7618):464-465 